\title{
Inelastic displacement demands in steel structures and their relationship with earthquake frequency content parameters
}

\author{
C. Málaga-Chuquitaype*and A. Y. Elghazouli \\ Department of Civil and Environmental Engineering, Imperial College London, UK
}

\begin{abstract}
SUMMARY
This paper deals with the estimation of peak inelastic displacements of single-degree-of-freedom (SDOF) systems, representative of typical steel structures, under constant relative strength scenarios. Mean inelastic deformation demands on bi-linear systems (simulating moment resisting frames) are considered as the basis for comparative purposes. Additional SDOF models representing partially-restrained (PR) and concentrically-braced (CB) frames are introduced and employed to assess the influence of different forcedisplacement relationships on peak inelastic displacement ratios. The studies presented in this paper illustrate that the ratio between the overall yield strength and the strength during pinching intervals is the main factor governing the inelastic deformations of PR models and leading to significant differences when compared against predictions based on bi-linear structures, especially in the short-period range. It is also shown that the response of CB systems can differ significantly from other pinching models when subjected to low or moderate levels of seismic demand, highlighting the necessity of employing dedicated models for studying the response of $\mathrm{CB}$ structures. Particular attention is also given to the influence of a number of scalar parameters that characterize the frequency content of the ground-motion on the estimated peak displacement ratios. The relative merits of using the average spectral period $T_{a v e r}$, mean period $T_{m}$, predominant period $T_{g}$, characteristic period $T_{c}$ and smoothed spectral predominant period $T_{o}$ of the earthquake ground-motion, are assessed. This paper demonstrates that the predominant period, defined as the period at which the input energy is maximum throughout the period range, is the most suitable frequency content scalar parameter for reducing the variability in displacement estimations. Finally, non-iterative equivalent linearization expressions based on the secant period and equivalent damping ratios are presented and verified for the prediction of peak deformation demands in steel structures. Copyright (c) 2010 John Wiley \& Sons, Ltd.
\end{abstract}

Received ...

KEY WORDS: steel structures; earthquake displacement demands; inelastic displacement ratios; groundmotion frequency content; equivalent linearization

\section{INTRODUCTION}

Current earthquake performance-based design and assessment methodologies pay special attention to the reliable determination of structural displacements [1]. Although such seismic demands can be calculated through sophisticated non-linear response history analyses, their application in practical assessment is still hampered by the considerable time, costs and expertise they require. Therefore, there is a need for simplified yet reliable methods for the estimation of structural seismic demands. Moreover, although in many cases structures do not behave as single-degree-of-freedom (SDOF) systems, various studies have shown that equivalent SDOF models can provide the basis for the estimation of global demands on building structures [2,3,46]; accordingly, recent recommendations

*Correspondence to: c.malaga@imperial.ac.uk

${ }^{\dagger}$ Please ensure that you use the most up to date class file, available from the EQE Home Page at

http://www3.interscience.wiley.com/journal/1922/home 
for the evaluation of maximum deformations in buildings are based on such equivalent SDOF representations [5, 6].

Numerous studies have used SDOF models to develop probabilistic estimations of peak inelastic displacements under several suites of ground-motions [7-14]. Some of these studies have focused on the estimation of strength ratios for systems of known ductility, distinguishing between stiff and soft soils and providing relationships that can be useful in the design of new structures to attain specified target ductility levels $[8,10]$. On the other hand, other studies have evaluated peak displacement demands for strength-defined structures and have provided relationships which are useful for the seismic assessment of existing buildings [9, 12]. More recently, Bozorgnia et al. [14] performed a detailed investigation on inelastic deformations in SDOF systems based on predictive equations formulated on the basis of a large database including 3122 records. This study verified the applicability of the "equal displacement rule" originally proposed by Veletsos, Newmark and Hall $[15,16]$, and assessed the influence of several earthquake parameters on the inelastic displacement ratios of elastic-perfectly plastic systems.

Most of the available studies offer statistical results based primarily on elastic-plastic SDOF systems, and those studies that include pinching behaviour incorporate simultaneously severe levels of strength deterioration typical of reinforced concrete structures [12,13,17-19]. Goda et al. [19] concluded that the effects of degradation plus pinching can be significant and must be considered through the use of period-dependent and hysteretic-dependent factors. In the latter study analyses on three structures (with periods of $0.2,1.0$ and 2.0 seconds) were performed for different values of normalized yield strength and for three levels of coupled pinching-degradation. Such levels of concurrent pinching and deterioration differ notably from pinching hysteresis of typical partially-restrained (PR) or concentrically-braced (CB) systems where no significant deterioration in strength is evident up to considerably high levels of deformation demand [20-22]. One of the few studies that differentiate between the influence of degradation and pinching characteristics is that by Song and Pincheira [17]. They observed that the influence of monotonic and cyclic strength as well as stiffness degradation and pinching is important only for structures built on soft soils with virtually no effect observed for ground-motions recorded on rock or stiff soils. However, pinching loops were constrained to be origin-centred and only 12 records were used. Therefore, there is a clear need for a full characterization of the influence of different pinching ratios within the range typically observed in PR structures, which commonly do not exhibit simultaneous severe strength degradation [20,21]. Similarly, the tension elongation and compression buckling of bracing members in CB structures induce severe levels of pinching behaviour which are typically unaccompanied by major strength deterioration and can also build characteristic dynamic effects which warrant specific consideration [22].

The influence of frequency content of the ground-motion has long been recognized as a crucial parameter for the accurate estimation of seismic demands $[15,16]$. Although response or Fourier spectra fully characterize the frequency content of a ground-motion and are always illustrative during the design and assessment processes, the use of a single scalar parameter representative of the record frequency content can offer some practical advantages. For example, Chopra and Chintanapakdee [23] introduced the ratio of structural period $(T)$ over the characteristic period of the ground-motion $\left(T_{c}\right)$ to better characterize the difference in inelastic deformation ratios between near-fault and far-fault ground-motions. Vidic et al. [7] proposed simplified expressions for the estimation of strength reduction factors utilizing a ground-motion dependent period referred to as $T_{1}$ (calculated as an approximation of $T_{c}$ ). Miranda $[2,10,12,24]$ recommended the use of the predominant period $\left(T_{g}\right)$ in order to improve estimations of peak deformation demands on structures built on soft soils sites. Shimazaki and Sozen [25], Uang and Maarouf [26], Tiwari and Gupta [27] and Chakraborti and Gupta [28] also used the predominant period $\left(T_{g}\right)$ to better characterize seismic deformation demands and studied the influence of various earthquake and site parameters on the displacement estimations. Rathje et al. [29] developed empirical relationships for four frequency content parameters and encouraged the use of $T_{m}$ as a robust representation of a strong ground-motion, particularly its long period frequency content, in light of the relation of $T_{m}$ with the Fourier Amplitude Spectrum. Yet, a comparison of the relative merits of the use of one 
scalar frequency content parameter over others in the context of the prediction of seismic inelastic demands has not been carried out, particularly for PR and CB structures.

In general, simplified methodologies for the estimation of peak structural deformations have largely followed two approaches: (i) a seismic coefficient approach (where the response of a non-linear structure is obtained on the basis of the empirically modified response of an elastic system with the same lateral stiffness and viscous damping [30]), or (ii) an equivalent linearization approach (in which the inelastic behaviour is accounted for by considering the response of an equivalent linear system with lower equivalent stiffness and higher viscous damping [31]). Owing to its versatility, the equivalent linearization approach also forms the basis of seismic assessment procedures in current European provisions [5,32]. Furthermore, several equivalent linearization models have been proposed which can be grouped according to the definition of equivalent parameters employed. A first set of studies define the equivalent period as the period related to the secant stiffness at peak inelastic displacement and obtain the equivalent damping from energy balance relationships [33] or statistical analyses [34]. A second set of studies derive period and damping pairs through various mathematical optimization procedures [35, 36]. In most cases the proposed equivalent damping and period expressions are derived as functions of target ductility levels which are unknown when assessing the response of existing structures. Only Lin and Lin [37] and Goda and Atkinson [38] propose equivalent linear systems with parameters defined in terms of strength ratios suitable for the evaluation of existing structures. Goda and Atkinson [38] present prediction equations of equivalent linear models based on optimal periods for non-degrading, degrading and degrading plus pinching structures. Lin and Lin [37] suggest equivalent linear models based on the secant period for bi-linear systems with varying strain hardening stiffness. However, equivalent linearized models for the estimation of inelastic structural response of PR and $\mathrm{CB}$ structures are lacking. Besides, the use of the secant period as the equivalent period in equivalent SDOF models should be considered, as it leads to maximum inelastic displacement and acceleration occurring at the intersection of the capacity and demand diagrams for a given equivalent damping, hence providing engineers with a direct graphical comparison tool.

In light of the above discussion, this paper seeks to improve the understanding of the deformation response of SDOF systems representative of commonly used steel structures, with the aim of informing their seismic assessment. Therefore, the objective of this paper is threefold:

(i) Firstly, to offer a detailed characterization of inelastic demands in steel structures with particular emphasis on pinching SDOFs representative of PR and CB steel frames.

(ii) Secondly, to assess the influence of different frequency content parameters on the inelastic demands of SDOF systems simulating typical steel structures with both bi-linear and pinching hysteresis.

(iii) Finally, and on the basis of the findings of the previous two stages, propose simplified expressions for the assessment of displacement demands for steel structures in the form of non-iterative equivalent linearisation procedures based on secant periods.

\section{STRUCTURAL SYSTEMS AND EARTHQUAKE GROUND-MOTIONS}

Bi-linear (i.e. elastic-perfectly plastic) systems are used in this study as benchmark models for comparison purposes. In addition, the response of SDOF models representative of PR and CB structures is considered, for which the characteristics of the structural models employed are described below.

\subsection{PR Pinching Model}

The Modified Richard Abbott model as proposed and validated by Nogueiro et al. [39] is used here to represent the response of Partially-Restrained (PR) steel structures. The Modified Richard Abbott model is based on the alternation between two limiting curves of the Richard Abbott 


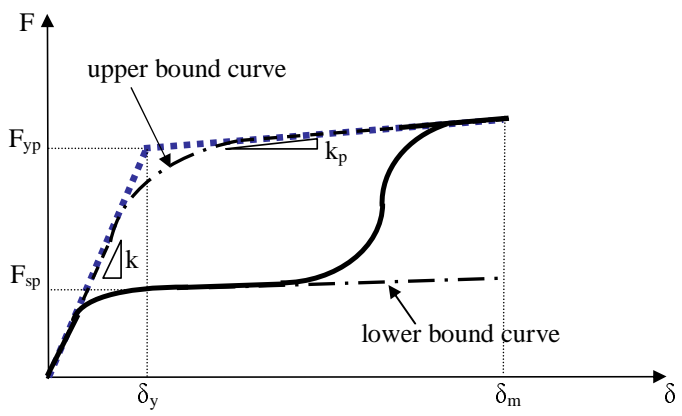

Bi-linear backbone - - - Limiting curves $\quad$ Modified Richard-Abbot

(a) Bi-linear and Modified Richard-Abbott force-deformation relationships.

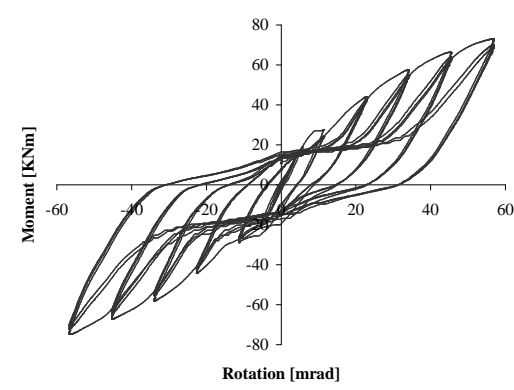

(b) Experimental moment-rotation relationship of a top, seat and web angle connection [20].

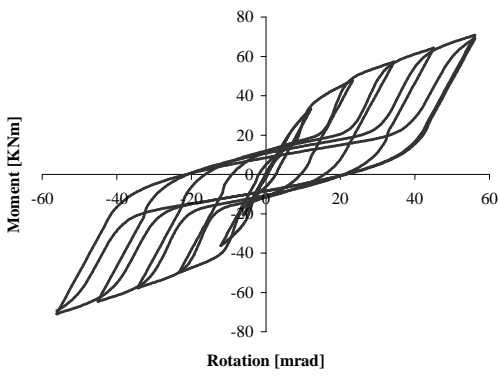

(c) Moment-rotation relationship of the same top, seat and web angle connection specimen estimated through a Modified Richard-Abbott model.

Figure 1. PR behaviour and modelling.

type [40]. As shown in Figure 1a, the boundary curves are characterized by their initial stiffness $(k)$, post-elastic stiffness $\left(k_{p}\right)$ and strength capacities $\left(F_{s p}\right.$ and $F_{y p}$ for the lower and upper bound curves, respectively) where $F_{y p}$ is the yield strength corresponding to the yield deformation $\delta_{y}$. Also presented in Figure 1a is the corresponding bi-linear approximation of the Modified Richard Abbott backbone. The pinching factor $(P)$ is defined here as the ratio between the structural capacity during pinching intervals and the overall capacity:

$$
P=F_{s p} / F_{y p}
$$

Additionally, the transition from the lower to the upper curve depends on a shape parameter $(t)$ defined as [39]:

$$
t=\left(\frac{\left(\delta / \delta_{\text {lim }}\right)^{t_{1}}}{\left(\delta / \delta_{\text {lim }}\right)^{t_{1}}+1}\right)^{t_{2}}
$$

where $\delta$ is the deformation (displacement or rotation), and $t_{1}, t_{2}$ and $\delta_{\text {lim }}$ are experimentally calibrated parameters. The parameter $\delta_{\text {lim }}$ is related to the maximum deformation $\delta_{m}$ by:

$$
\delta_{\text {lim }}=C\left(\left|\delta_{0}\right|+\delta_{m}\right)
$$

where $\left|\delta_{0}\right|$ is the absolute value of the deformation corresponding to the starting point of the current excursion, and $C$ is a calibration parameter taken as 1 in the current study in accordance with typical values reported for several connection details [39]. Figures $1 \mathrm{~b}$ and $1 \mathrm{c}$ compare the moment rotation responses of an experimentally observed semi-rigid connection [20] and its respective PR model.

\subsection{CB Pinching Model}

Figure 2 presents the SDOF model used to study the response of Concentrically-Braced (CB) frames. The idealized SDOF consists of pin-connected rigid members forming a 1-storey high 2-bay 


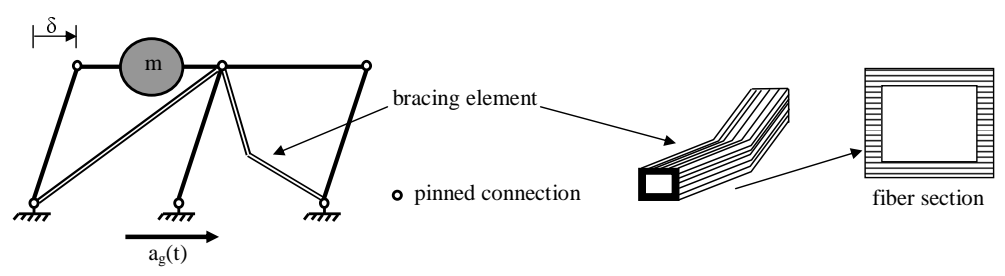

(a) Model of a CB SDOF subjected to ground-motion.

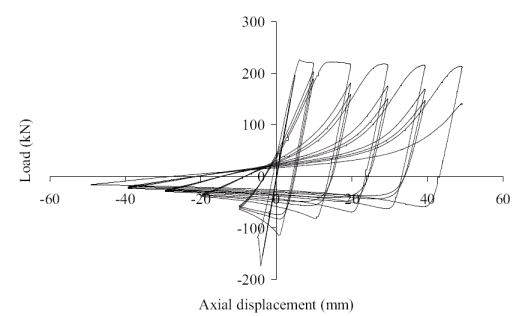

(b) Experimental force-displacement relationship of a steel brace with normalized slenderness $(\bar{\lambda})$ of $1[43]$.

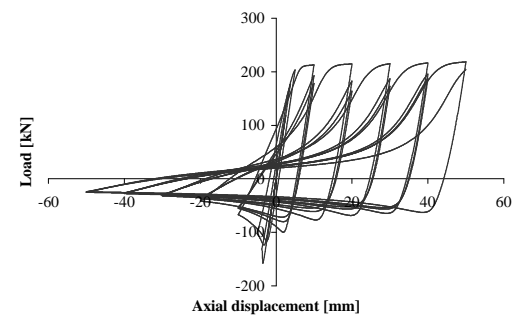

(c) Force-displacement relationship of the same brace specimen estimated by means of fiber-based buckling elements.

Figure 2. CB behaviour and modelling.

CB frame. The structure is modelled in OpenSees [41] with due account for geometric and material non-linearities. The braces are modelled using fiber-based buckling elements following the approach proposed by Uriz and Mahin [42]. A typical comparison of experimental [43] and predicted axial force-displacement relationships of a brace member is also depicted in Figure 2. It is important to note that the necessary structural parameters such as yield strength and initial period were obtained from incremental monotonic (pushover) and Eigenvalue analyses on the corresponding CB models, respectively. Therefore the relative contribution of tension and compression braces is directly accounted for. These definitions are consistently applied throughout this paper.

\subsection{Ground-motions considered}

A total of 100 records from 27 earthquakes with magnitudes $M_{w}$ ranging from 5.65 to 7.51 , and distances ranging from 6.28 to $293 \mathrm{Km}$, were used in this study. The acceleration records were obtained from the PEER-NGA database (http://peer.berkeley.edu/nga), and involve different site classes (according to the NEHRP classification) in order to address the impact of site conditions on the variability in inelastic response. Special attention was given to the lowest usable frequency in order to avoid undesired noise and filtering effects. Table I summarizes the catalogue of earthquakes used while a more detailed information can be found elsewhere [44]. The numbers in parenthesis under the heading NEHRP site class represent the number of records associated with each soil site group. Figure 3 presents the median acceleration response spectra normalized by Peak Ground Acceleration (PGA) for different soil classes. It is worth noting that Site Class C in the NEHRP provisions (with $360<v_{s, 30}<760 \mathrm{~m} / \mathrm{s}$ ) is broadly equivalent to Ground Type B as defined in Eurocode 8 (with $360<v_{s, 30}<800 \mathrm{~m} / \mathrm{s}$ ). Similarly, based on the limiting values of shear-wave velocity in the upper 30 metres $\left(v_{s, 30}\right)$, NEHRP Classes $\mathrm{D}$ and $\mathrm{E}$ are equivalent to Ground Types $\mathrm{C}$ and D in Eurocode 8 [5].

\subsection{Scope of parametric analysis}

A statistical study was performed on the peak inelastic displacement demands for several SDOF systems with 5\% viscous damping under constant strength ratio scenarios. The inelastic displacement ratio $\left(C_{R}\right)$ is defined as the ratio between the peak lateral inelastic displacement 
Table I. Summary of earthquake ground-motions used in this study.

\begin{tabular}{|c|c|c|c|c|c|c|c|}
\hline \multirow{2}{*}{ Earthquake name } & \multirow{2}{*}{$\begin{array}{c}\text { Magnitude } \\
\mathbf{M}_{\mathbf{w}} \\
\end{array}$} & \multirow{2}{*}{$\begin{array}{c}\text { Number of } \\
\text { records }\end{array}$} & \multicolumn{2}{|c|}{ Distance $[\mathrm{km}]$} & \multicolumn{2}{|c|}{ PGA $\left[\mathrm{cm} / \mathrm{s}^{2}\right]$} & \multirow{2}{*}{$\begin{array}{l}\text { NEHRP } \\
\text { site class }\end{array}$} \\
\hline & & & Min. & Max. & Min. & Max. & \\
\hline 1992 Cape Mendocino & 7.01 & 4 & 10.36 & 53.34 & 151.11 & 1468.85 & $C(2) D(2)$ \\
\hline 1986 Chalfant Valley-01 & 5.77 & 2 & 10.54 & 10.54 & 202.59 & 279.58 & $\mathrm{D}(2)$ \\
\hline 1986 Chalfant Valley-02 & 6.19 & 2 & 14.33 & 14.33 & 392.12 & 438.32 & $\mathrm{D}(2)$ \\
\hline 2002 Denali, Alaska ${ }^{\ddagger}$ & 7.9 & 6 & 290.70 & 293.06 & 10.02 & 22.39 & $\mathrm{E}(6)$ \\
\hline 1999 Duzce, Turkey ${ }^{\ddagger}$ & 7.14 & 4 & 24.26 & 206.09 & 24.73 & 144.64 & $C(2) E(2)$ \\
\hline 1976 Friuli, Italy-01 & 6.5 & 2 & 20.23 & 20.23 & 308.83 & 344.65 & $\mathrm{C}(2)$ \\
\hline 1976 Gazli, USSR & 6.8 & 2 & 12.82 & 12.82 & 596.70 & 703.92 & $\mathrm{C}(2)$ \\
\hline 1999 Hector Mine & 7.13 & 2 & 52.29 & 52.29 & 143.04 & 186.05 & $C(2)$ \\
\hline 1979 Imperial Valley-06 & 6.53 & 4 & 22.65 & 30.35 & 216.87 & 320.53 & $\mathrm{D}(2) \mathrm{E}(2)$ \\
\hline 1980 Irpinia, Italy-01 & 6.90 & 4 & 22.65 & 30.35 & 136.71 & 350.97 & $\mathrm{~B}(4)$ \\
\hline 1952 Kern County & 7.36 & 2 & 43.39 & 43.39 & 153.00 & 174.41 & $\mathrm{C}(2)$ \\
\hline 1995 Kobe, Japan & 6.90 & 2 & 25.40 & 25.40 & 284.57 & 304.56 & $\mathrm{~B}(2)$ \\
\hline 1999 Kocaeli, Turkey ${ }^{*}$ & 7.51 & 6 & 47.03 & 112.26 & 134.64 & 243.94 & $\mathrm{~A}(2) \mathrm{B}(2) \mathrm{E}(2)$ \\
\hline 1992 Landers & 7.28 & 2 & 44.02 & 44.02 & 713.03 & 774.17 & $\mathrm{C}(2)$ \\
\hline 1994 Little Skull Mtn,NV & 5.65 & 3 & 14.12 & 30.17 & 116.71 & 208.81 & $\mathrm{~B}(3)$ \\
\hline 1989 Loma Prieta ${ }^{\star}$ & 6.93 & 15 & 16.51 & 114.87 & 94.64 & 388.07 & $\mathrm{~B}(3) \mathrm{D}(2) \mathrm{E}(8)$ \\
\hline 1990 Manjil, Iran & 7.37 & 2 & 37.90 & 37.90 & 486.92 & 504.78 & $\mathrm{C}(2)$ \\
\hline 1984 Morgan Hill & 6.19 & 2 & 38.20 & 38.20 & 190.58 & 196.59 & $\mathrm{D}(2)$ \\
\hline 1986 N. Palm Springs & 6.06 & 2 & 6.28 & 6.28 & 201.08 & 214.06 & $\mathrm{D}(2)$ \\
\hline 1985 Nahanni, Canada & 6.76 & 2 & 6.80 & 6.80 & 959.25 & 1074.88 & $\mathrm{C}(2)$ \\
\hline 2002 Nenana Mountain, Alaska & 6.70 & 8 & 275.28 & 277.70 & 7.08 & 10.73 & $\mathrm{E}(8)$ \\
\hline 1994 Northridge-01 & 6.69 & 12 & 18.99 & 45.77 & 110.19 & 1554.79 & $A(4) B(8)$ \\
\hline 1971 San Fernando & 6.61 & 2 & 31.55 & 31.55 & 145.57 & 148.98 & $\mathrm{C}(2)$ \\
\hline 1986 San Salvador & 5.80 & 2 & 9.54 & 9.54 & 398.66 & 600.51 & $\mathrm{D}(2)$ \\
\hline 1987 Superstition Hills-02 & 6.54 & 2 & 29.91 & 29.91 & 113.76 & 152.94 & $\mathrm{D}(2)$ \\
\hline 1978 Tabas, Iran & 7.35 & 2 & 55.24 & 55.24 & 819.93 & 835.58 & $\mathrm{~B}(2)$ \\
\hline 1981 Westmorland & 5.90 & 2 & 20.47 & 20.47 & 152.18 & 237.25 & $\mathrm{D}(2)$ \\
\hline
\end{tabular}

${ }^{\ddagger}$ Records used for the study on the influence of frequency content parameters

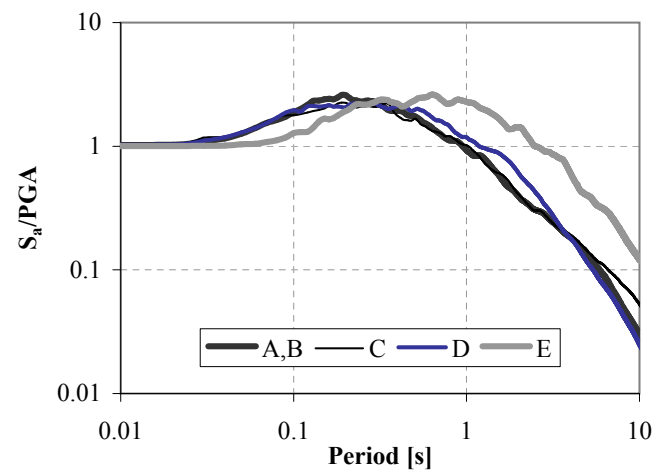

Figure 3. Median normalized acceleration response spectra for different soil classes.

$\left(\delta_{\text {inelastic }}\right)$ and the peak lateral elastic displacement demand $\left(\delta_{\text {elastic }}\right)$ on an infinitely elastic SDOF with the same mass and initial stiffness:

$$
C_{R}=\frac{\delta_{\text {inelastic }}}{\delta_{\text {elastic }}}
$$

$\delta_{\text {inelastic }}$ is calculated from response history analyses on structures with constant relative strength in proportion to the strength required to keep the system elastic $\left(F_{y}\right)$ which in the case of PR systems takes the value of $F_{y p}$ in Figure 1a. The constant relative strength scenarios are characterized by the strength ratio $R$ defined as:

$$
R=\frac{m S_{a}}{F_{y}}
$$


where $m$ is the mass of the system and $S_{a}$ is the acceleration spectral ordinate. Four values of lateral strength ratios $R$ were considered (i.e. $R=2,3,4$ and 5).

As noted before, the shape of the pinching loop for the PR Modified Richard Abbott model depends on the pinching ratio $P$ and two empirically calibrated coefficients $\left(t_{1}\right.$ and $\left.t_{2}\right)$. A sensitivity study was performed in order to assess the effects of the shape coefficients $t_{1}$ and $t_{2}$ on the prediction of inelastic displacements [44]. It was concluded that the variation of $t_{1}$ and $t_{2}$ over a typical practical range does not introduce notable differences in the estimations of mean peak displacements, and hence a constant pair of $\left(t_{1}, t_{2}\right)=(15,0.5)$ can be considered as representative of PR configurations and is hence used throughout this study. On the other hand, the influence of $P$ on the inelastic displacement ratios is expected to be significant, as discussed in subsequent sections. Therefore, parametric analyses were performed for 3 levels of pinching (i.e. $P=0.15,0.3$ and 0.6) representative of pinching levels usually observed in PR connections. Similarly, the effects of 4 normalized slenderness values $(\bar{\lambda}=0.9,1.3,1.7$ and 2.1) characterizing practical ranges of conventional braced frame designs were considered for CB models. It should be noted that only square hollow section members of cross-section Class 1 according to Eurocode 3 [45] were used as braces.

$C_{R}$ ratios were calculated for a range of initial structural periods $(T)$ between 0.10 seconds and 5 seconds. In the case of bi-linear and PR systems, intervals of 0.05 for periods less than 1.5 seconds were used whereas intervals of 0.2 seconds for structures with longer periods were employed. In the case of CB models, initial elastic periods between 0.1 and 1.5 seconds with 15 intervals of 0.1 second were considered while intervals of 0.2 seconds were used for structures with longer periods.

It is interesting to note that the monotonic force-displacement relationships of PR and CB models are broadly similar, despite being dependent on different parameters and modelling assumptions, For example, Figure 4 depicts the hysteretic behaviour of a PR model with $P=0.15$ and a CB model with $\bar{\lambda}=2.1$. The bi-linear backbone is also presented in Figure 4a for comparison. It can be observed from Figure 4a that some differences in cyclic behaviour may occur during the initial elastic stage and during loading at large inelastic displacements. Nonetheless, based on the apparent resemblance in Figure 4a, it would seem reasonable to consider using displacement predictions based on pinching SDOF models as proxies for CB structures. However, due to the intricate tensioncompression balance within pairs of bracing members undergoing dynamic response, notable differences in the structural hysteresis loops may arise under earthquake loading as illustrated in Figure 4b. This difference in deformation estimations highlights the necessity for dedicated CB models that incorporate realistic representations of the brace tension and buckling behaviour.

It is worth noting that results for structural response parameters other than peak displacement (e.g. Fatigue damage and Park and Ang damage indeces), as well as the effects of various postelastic stiffness, have also been examined. For brevity, these results are not included here but related discussions can be found elsewhere [44].

\section{ASSESSMENT OF INELASTIC DEMANDS}

The results of more than 140000 response history analyses, based on the considerations and definitions described in previous sections, are presented and discussed herein. Mean inelastic displacement ratios were computed by averaging the results for each period, strength ratio and hysteretic model. On the basis of the spectral shapes depicted in Figure 3, a clear distinction is made between moderately stiff to stiff soils sites (Classes A, B, C and D) and soft soils sites (Class E) for purposes of presentation and discussion $[10,12]$. The effects of structural model characteristics, strength demand and soil conditions on inelastic displacement ratios are discussed below.

\subsection{Inelastic displacement demands}

Bi-linear Models

Figure 5 presents mean inelastic displacement ratios for moderately stiff to stiff soils sites and soft 


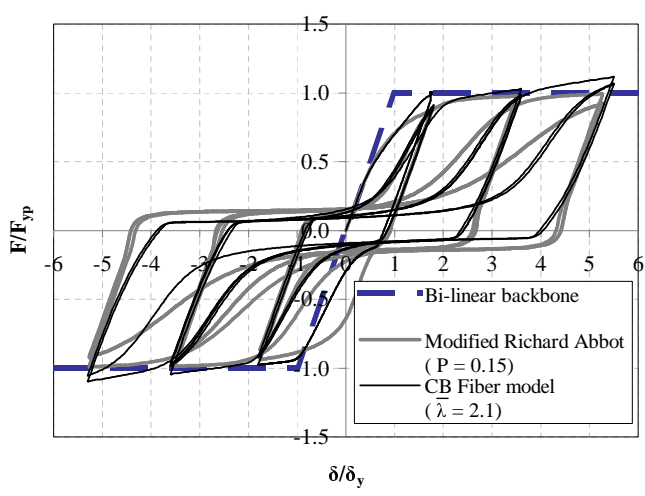

(a) Response under cyclic loading.

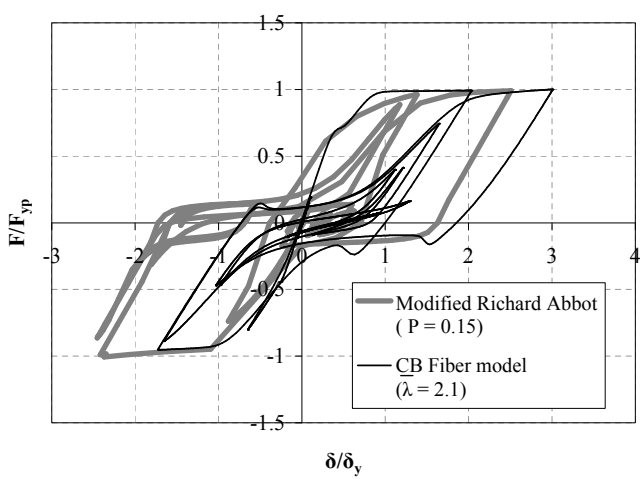

(b) Response under the Pacoima Dam record of the Northridge Earthquake.

Figure 4. Comparison of hysteretic models of PR and CB systems.

soils sites together with their associated dispersion for bi-linear systems. The curves for $C_{R}$ follow the general trends observed by other researchers $[9,12]$ where inelastic displacement ratios increase as the structural period tends to zero. The dispersion, quantified here by means of the coefficient of variation $(C O V)$, is observed to increase with the strength ratio $R$ and decrease with increasing period. The values of $C O V$ presented in Figure $5 \mathrm{~b}$ are also largely in accordance with findings from previous studies [9].

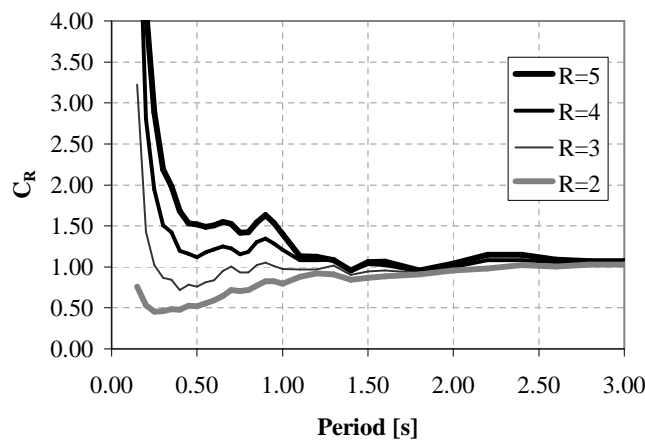

(a) Mean inelastic displacement ratios for moderately stiff to stiff soil ground-motions.

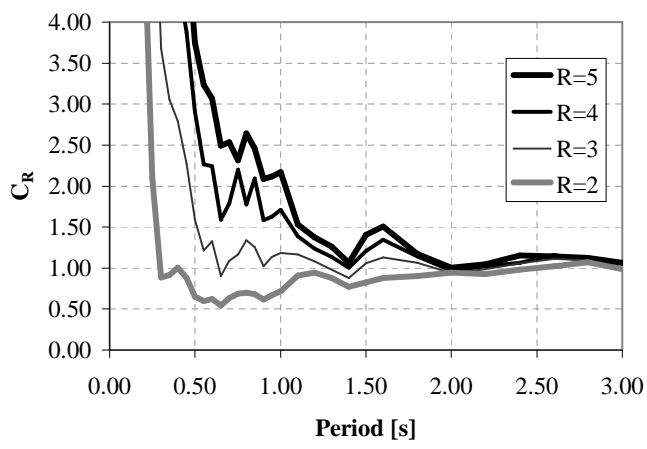

(c) Mean inelastic displacement ratios for soft soil ground-motions.

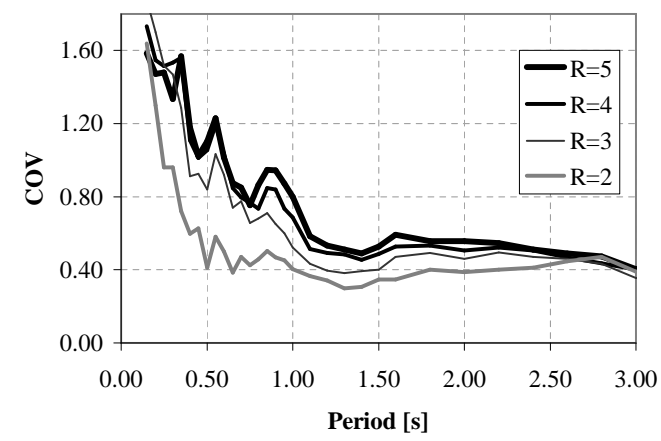

(b) Coefficients of variation of inelastic displacement ratios for moderately stiff to stiff soil ground-motions.

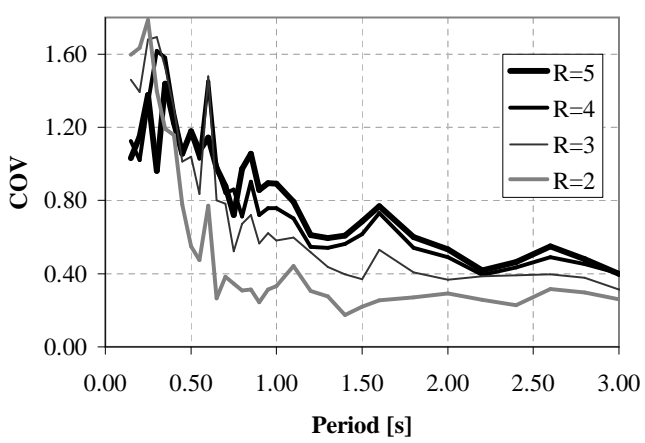

(d) Coefficients of variation of inelastic displacement ratios for soft soil ground-motions.

Figure 5. Inelastic displacement demands for bi-linear systems. 


\section{PR Models}

Figure 6 depicts mean inelastic peak displacement ratios of PR models normalized by the mean inelastic displacement ratios of the corresponding bi-linear systems. It can be observed from Figure 6a that for periods longer than 1 second, the results of bi-linear and PR models with $P=0.3$ are broadly coincident and that this occurs regardless of the strength ratio. However, for stiffer structures, with initial periods lower than 1 second, PR models exhibit an increasingly higher displacement that can reach values of twice the expected displacements in bi-linear systems. Similar results to those presented in Figure 6a were found for other levels of pinching.

Based on the negligible variability in displacement ratios as a function of $R$ observed in Figure 6a, Figure $6 \mathrm{~b}$ presents the normalized mean displacement ratios of $\mathrm{PR}$ over bi-linear models for different levels of pinching averaged over all $R$ values considered (i.e. 2, 3, 4 and 5). It can be observed from Figure $6 \mathrm{~b}$ that there is some degree of dependence of $C_{P R} / C_{R}$ ratios on the level of pinching, particularly for relatively stiff systems. As expected, the displacement amplification of short-period PR models built on moderate to stiff soils with respect to bi-linear predictions tend to increase for lower values of $P$ owing to the reduced energy dissipation in systems with higher pinching levels.

Figure 6 also presents the results for soft soils sites (Figures $6 c$ and $6 \mathrm{~d}$ ). Similar trends as those identified for moderate to stiff soils (Figures 6a and 6b) are observed, although higher inelastic demands and increased variability with respect to $R$ are evident in the case of soft soils. Additionally, for structures with elastic periods longer than 2 seconds, peak displacements of PR models are on average about $10 \%$ lower than those observed for bi-linear structures, even for large pinching levels (e.g. $P=0.15$ in Figure $6 \mathrm{~d}$ ). The levels of dispersion were also found to be similar to those observed for bi-linear systems and the COV followed the same trends (i.e. increasing with larger strength ratios $R$ and decreasing with increasing structural flexibilities).

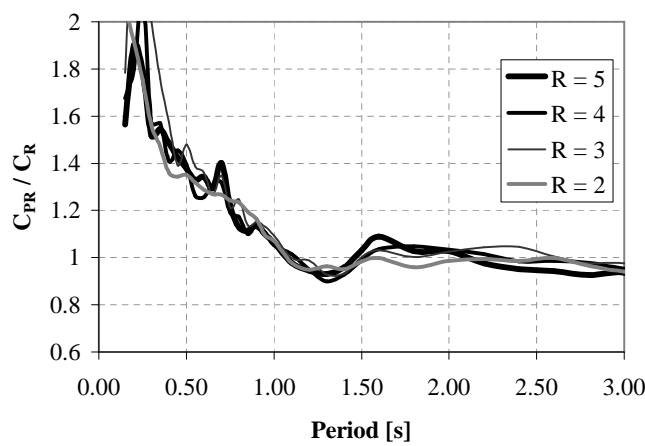

(a) Moderately stiff to stiff soil ground-motions. $P=$ 0.3 .

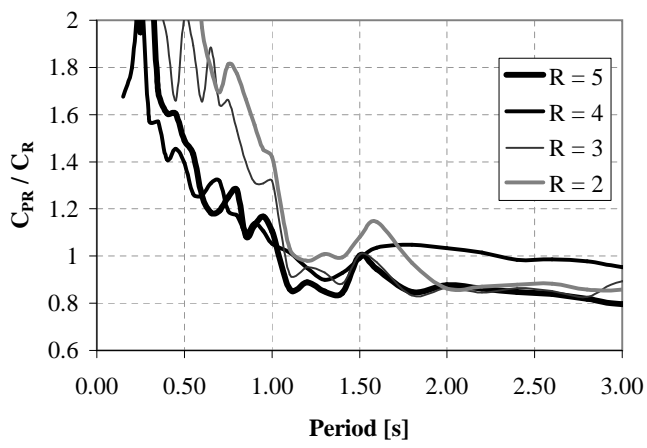

(c) Soft soil ground-motions. $P=0.3$.

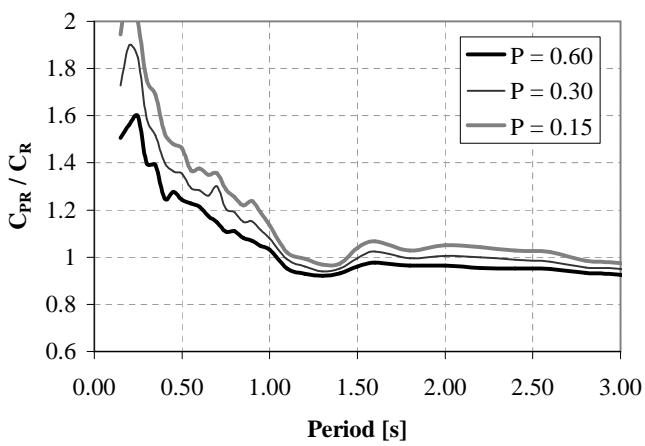

(b) Average for all strength values on moderately stiff to stiff soils as a function of pinching factor $(P)$.

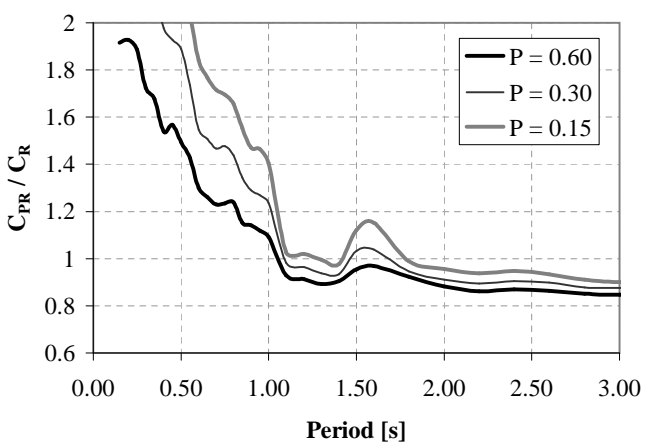

(d) Average for all strength values on soft soils as a function of pinching factor $(P)$

Figure 6. Mean inelastic displacement ratios of PR systems normalized by mean displacement ratios of bi-linear systems. 


\section{CB Models}

Figure 7 presents the mean inelastic displacement ratios of $\mathrm{CB}$ systems normalized by the corresponding inelastic displacement ratios of bi-linear structures. It can be observed from Figure $7 \mathrm{a}$ that the mean displacements obtained with a CB fiber model exceed the bi-linear predictions most notably for structures with $T \leq 1$ second, while peak deformations on CB structures can be slightly lower than their corresponding elastic-perfectly plastic estimations for periods longer than 2 seconds. This effect becomes more pronounced as the structural period shortens and as the level of inelastic behaviour decreases, particularly for moderate to stiff soils. The same increment in average peak displacements with decreasing period is evident for CB structures on soft soils (Figure 7c). Conversely, a grater variability of peak displacements with strength ratios can be observed for soft soils.

The average ratio of peak displacement values for a constant $R=2$ as a function of normalized slenderness is depicted in Figures $7 \mathrm{~b}$ and $7 \mathrm{~d}$ for moderate to stiff soils and soft soils, respectively. Slightly higher displacements are expected when more slender braces are used on stiffer soils sites for structures with elastic periods up to 1.7 seconds due to the improved energy dissipation characteristics of the hysteresis of more stocky braces (Figure $7 \mathrm{~b}$ ) whereas the brace slenderness influence is negligible in the long period range, most notably for CB structures with $1.3 \leq \bar{\lambda} \leq 2.1$. On the other hand, a clearer tendency towards greater peak deformations in more slender CB systems is manifested in the case of soft soils (Figure 7d) for periods up to 1 second. In particular, marked lower displacements are evident for CB structures incorporating braces with normalized slenderness of $\bar{\lambda}=0.9$ for the period range between 0.4 and 0.9 second. Conversely, for longer periods, no direct relationship between the ratio of mean displacements and the brace slenderness can be appreciated.

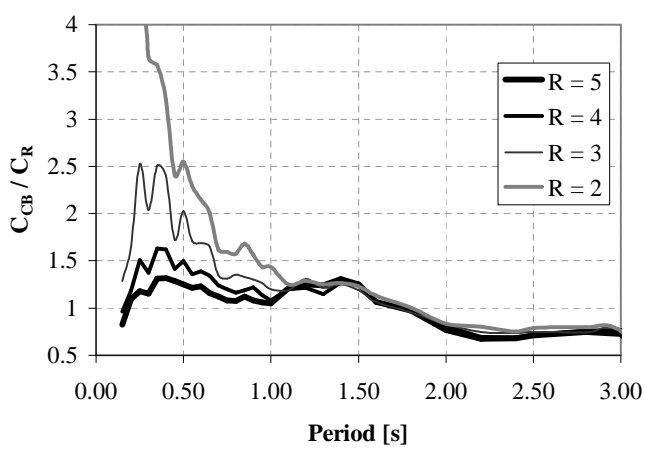

(a) Moderately stiff to stiff soil ground-motions. (For $\bar{\lambda}=1.3)$.

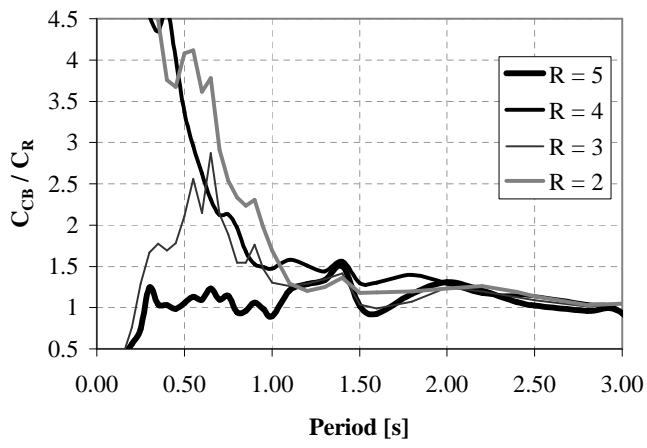

(c) Soft soil ground-motions. (For $\bar{\lambda}=1.3$ ).

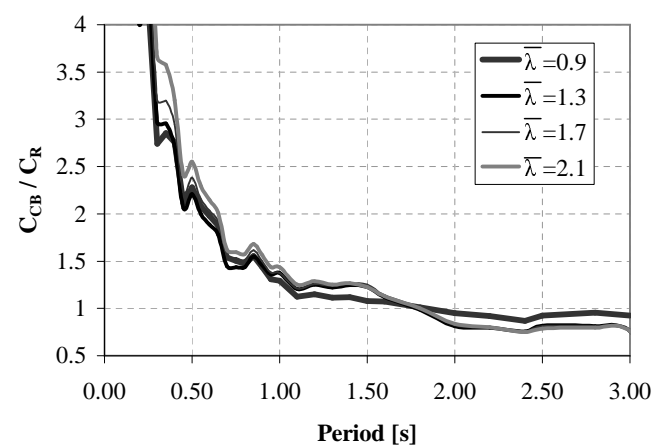

(b) Displacement ratio as a function of normalized slenderness $(\bar{\lambda})$ for moderate to stiff soil groundmotions and $R=2$.

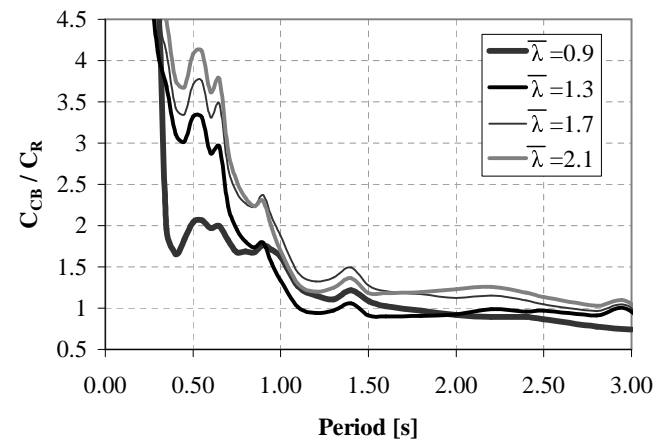

(d) Displacement ratio as a function of normalized slenderness $(\bar{\lambda})$ for soft soil ground-motions and $R=$ 2 .

Figure 7. Mean inelastic displacement ratios for CB systems normalized by mean ratios of bi-linear systems. 


\subsection{Effect of level of inelastic behaviour}

The influence of the lateral strength ratio on $C_{R}$ for PR and CB systems as compared against bi-linear systems is further studied with reference to Figures 8 and 9. Results are presented for mean peak inelastic displacements for structural periods of $0.4,1$ and 3 seconds for various PR pinching levels (Figure 8) and brace slenderness (Figure 9) for structures built on moderate to stiff soils.

\section{PR Models}

In the case of PR models, it can be seen that at $T=0.4$ second the average peak displacements increase almost linearly with lateral strength ratios $R$, an observation that is maintained for $T=1.0$ second albeit at lower deformation levels. A significant and steady dependence on the $P$ factor is also evident from Figures $8 \mathrm{a}$ and $8 \mathrm{~b}$, whereas no significant influence of $R$ or $P$ is observed for longer periods (e.g. $T=3.0$ seconds) where the equal displacement rule seems to be clearly applicable (Figure 8c).

\section{CB Models}

For CB systems (Figure 9) the influence of the level of lateral strength ratio on the displacement response is different as expected from the discussion on the dynamic behaviour in Section 2.4. Although $C_{R}$ values also increase with increasing $R$ for systems with $T=0.4$ second, the dependence on brace slenderness does not follow a clear trend. Also, while mean peak displacements in CB structures can be in the order of two times the corresponding displacements for bi-linear systems when $R=2$, such displacement amplification is reduced for higher strength ratios with CB systems experiencing lower displacement demands than elastic-perfectly plastic structures for $R \geq 4$ (Figure 9a). Additionally, the influence of the level of inelastic behaviour appears to be insignificant for CB structures with $T=1.0$ and $T=3.0$ seconds, and the equal displacement rule again seems to be largely applicable for CB structures in the long period range (Figures $9 \mathrm{~b}$ and $9 \mathrm{c}$ ).

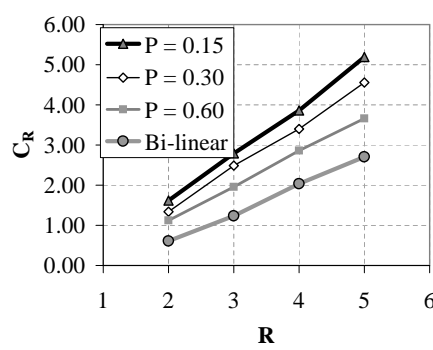

(a) $\mathrm{T}=0.4$ seconds

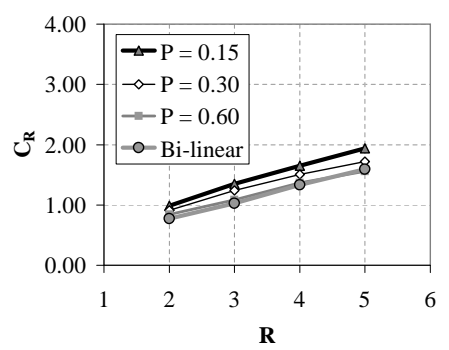

(b) $\mathrm{T}=1.0$ seconds

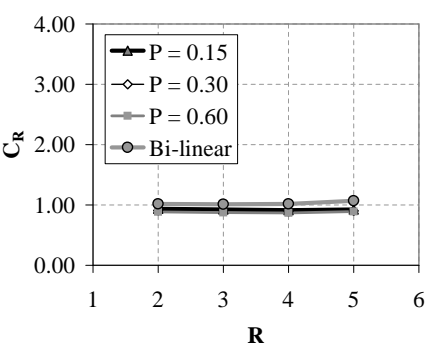

(c) $\mathrm{T}=3.0$ seconds

Figure 8. Effect of lateral strength ratio on the inelastic displacement ratios of PR systems.

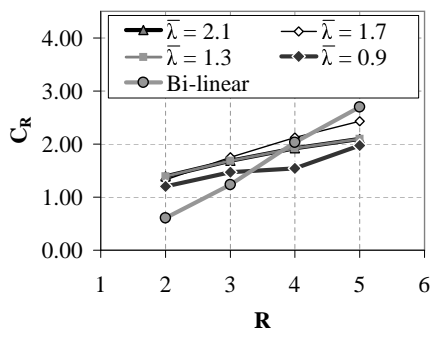

(a) $\mathrm{T}=0.4$ seconds

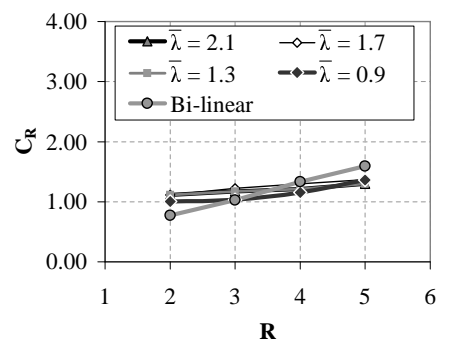

(b) $\mathrm{T}=1.0$ seconds

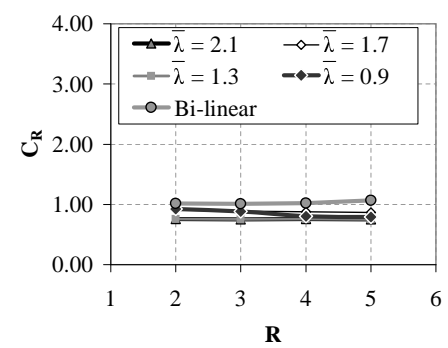

(c) $\mathrm{T}=3.0$ seconds

Figure 9. Effect of lateral strength ratio on the inelastic displacement ratios of CB systems. 


\subsection{Effect of soil conditions}

Besides the obvious differences in inelastic behaviour for stiff and soft soils sites, as highlighted in previous sections, it is also important to quantify the dissimilarities in inelastic displacements from ground-motions recorded in various moderate to stiff soil classes. Therefore, ratios of mean $C_{R}$ on each soil class to mean $C_{R}$ from all ground-motions on moderate to stiff soils (classes A,B,C and D) were computed and typical results are shown in Figure 10 while a more detailed discussion can be found elsewhere [44]. Owing to the negligible variability of $C_{R}$ ratios as a function of $R$ observed within each soil group [44], Figure 10 presents $C_{R}$ ratios averaged over all $R$ values considered (i.e. 2, 3, 4 and 5).

In the case of PR structures built on rock sites (Classes A and B in Figure 10a), neglecting local site effects by using the average of all soil classes in moderate to stiff soils (Classes A, B, C and D) would lead to an overestimation of less than $20 \%$ in mean inelastic displacement predictions for periods shorter than 1.7 seconds whereas practically no differences occur for longer periods. These peak levels of mean variations are maintained for PR structures built on other moderately stiff to stiff soils. On the other hand, when compared against the average of stiffer soils, the displacement amplification on soft soils sites is expected even for periods as long as 1.2 seconds and this soft site amplification increases notably with decreasing periods as shown in Figure 10a.

Similar levels of maximum mean variation as those previously highlighted for PR systems were observed for CB structures on moderately stiff to stiff soil conditions (Figure 10b). Also, as in the case of PR structures, CB systems on soft soils sites experience much larger displacements than those expected for CB systems on stiffer soils (Figure 10b) even in the long period range, highlighting the necessity for further dedicated studies and specific models for soft soils.

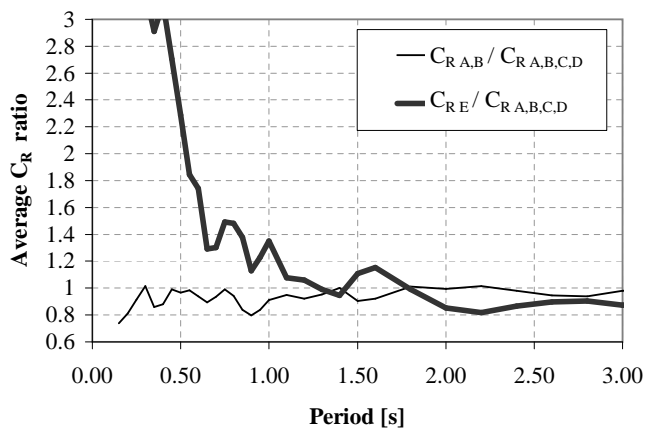

(a) Inelastic displacement ratios on Site Class A,B and E normalized by mean ratios from stiff soils averaged over all $\mathrm{R}$ values for PR systems.

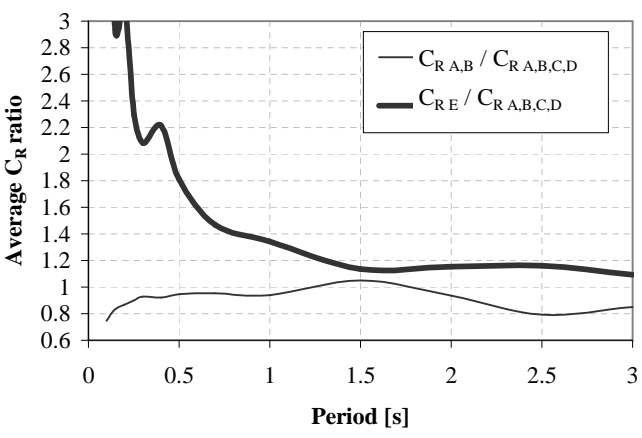

(b) Inelastic displacement ratios on Site Class A,B and E normalized by mean ratios from stiff soils averaged over all $\mathrm{R}$ values for $\mathrm{CB}$ systems.

Figure 10. Effect of soil conditions on displacement demands of PR and CB systems.

\section{INFLUENCE OF SCALAR FREQUENCY CONTENT PARAMETERS}

In order to assess the influence of the frequency content of the ground-motion, as characterized by a single scalar parameter, peak displacements were determined for bi-linear, PR and CB models with a number of ratios of $T$ normalized over a suite of five different period parameters. A sub-set of 30 records selected to reflect a wide range of frequency content characteristics was used as indicated in Table I. In the following sub-sections, the definitions of the frequency content parameters employed are presented followed by a discussion on the comparative merits of their use on the basis of the generated statistical results. 


\subsection{Frequency content parameters investigated}

Five commonly employed frequency content indicators are evaluated in the present study: the average spectral period $\left(T_{\text {aver }}\right)$, mean period $\left(T_{m}\right)$, predominant period $\left(T_{g}\right)$, characteristic period $\left(T_{c}\right)$ and smoothed spectral predominant period $\left(T_{o}\right)$.

The average spectral period $T_{\text {aver }}$ is calculated as:

$$
T_{\text {aver }}=\frac{\sum_{i=1}^{n} T_{i}\left(S_{a}\left(T_{i}\right) / P G A\right)^{2}}{\sum_{i=1}^{n}\left(S_{a}\left(T_{i}\right) / P G A\right)^{2}}
$$

where $T_{i}$ are equally spaced periods in the acceleration spectra with $0.05 \leq T_{i} \leq 4$ seconds, $\Delta T_{i}=$ 0.01 second, $S_{a}\left(T_{i}\right)$ is the spectral acceleration at $T_{i}$ and $P G A$ is the peak ground acceleration.

The mean period $T_{m}$ can be determined as:

$$
T_{m}=\frac{\sum_{i=1}^{n} 1 / f_{i} C_{i}^{2}}{\sum_{i=1}^{n} C_{i}^{2}}
$$

where $C_{i}$ is the Fourier amplitude coefficient at frequency $f_{i}$ with $0.25 \mathrm{~Hz} \leq f_{i} \leq 20 \mathrm{~Hz}$ and $\Delta f_{i}=0.01 \mathrm{~Hz}$.

The predominant period, $T_{g}$, is defined as the period at which the input energy is maximum throughout the period range and can be computed as the period at which the maximum ordinate of a 5\% damped relative velocity spectrum occurs [24].

The characteristic period $T_{c}$ is the period defining the transition between the acceleration sensitive and the velocity sensitive regions of the response spectra.

Finally, the smoothed predominant spectral period, $T_{o}$, is defined as:

$$
T_{o}=\frac{\sum_{i=1}^{n} T_{i} \ln \left(S_{a}\left(T_{i}\right) / P G A\right)}{\sum_{i=1}^{n} \ln \left(S_{a}\left(T_{i}\right) / P G A\right)}
$$

where $T_{i}$ are periods in the acceleration response spectrum equally spaced on a log axis with $S_{a} / P G A \geq 1.2$ and $\triangle \log T_{i}=0.01$.

The maximum and minimum values of $T_{a v e r}, T_{m}, T_{g}, T_{c}$ and $T_{o}$ for the sub-set of records employed in this section are summarized in Table II.

Table II. Summary of ground-motions frequency content indicators of the records used in this study.

\begin{tabular}{lccccccccccc}
\hline \multirow{2}{*}{ Earthquake name } & \multicolumn{2}{c}{$\mathbf{T}_{\text {aver }}[\mathbf{s}]$} & \multicolumn{2}{c}{$\mathbf{T}_{\mathbf{m}}[\mathbf{s}]$} & \multicolumn{2}{c}{$\mathbf{T}_{\mathbf{g}}[\mathbf{s}]$} & \multicolumn{2}{c}{$\mathbf{T}_{\mathbf{c}}[\mathbf{s}]$} & \multicolumn{3}{c}{$\mathbf{T}_{\mathbf{o}}[\mathbf{s}]$} \\
& min. & max. & min. & max. & min. & max. & min. & max. & min. & max. \\
\hline 2002 Denali, Alaska & 0.75 & 0.91 & 0.87 & 1.04 & 1.10 & 5.19 & 0.67 & 1.37 & 0.20 & 1.09 \\
1999 Duzce, Turkey & 0.70 & 0.78 & 1.20 & 1.31 & 1.96 & 2.24 & 0.77 & 1.24 & 0.72 & 0.93 \\
1979 Imperial Valley-06 & 1.09 & 1.38 & 0.29 & 0.34 & 2.26 & 4.58 & 0.44 & 0.50 & 0.14 & 0.18 \\
1999 Kocaeli, Turkey & 1.00 & 1.27 & 0.86 & 0.97 & 0.90 & 5.95 & 0.66 & 0.73 & 0.42 & 0.89 \\
1989 Loma Prieta & 0.94 & 1.25 & 0.59 & 0.78 & 0.67 & 2.23 & 0.52 & 0.86 & 0.49 & 1.06 \\
2002 Nenana Mountain, Alaska & 0.55 & 0.64 & 1.03 & 1.55 & 1.89 & 3.80 & 1.12 & 1.77 & 0.22 & 1.85 \\
\hline
\end{tabular}

\subsection{Results of statistical study}

A better characterization of the influence of the ground-motion frequency content on the dynamic response would enable a given structural response parameter to be determined with greater confidence (i.e. less dispersion) and using fewer analyses. This section evaluates the relative merits of considering a particular scalar frequency content parameter over others when evaluating central tendencies of peak inelastic displacements in bi-linear, PR and CB structures. For this purpose, the Coefficient of Variation (COV) is employed as the basis for comparisons in order to quantify the relative improvement in estimation that a given frequency content indicator offers when a set of 
ground-motions are scaled and/or catalogued according to it. Therefore, peak displacement ratios were calculated over a number of period ratios normalized over a range of characteristic period indicators. This section demonstrates that the consideration of $T_{g}$ as a frequency content indicator leads to an improved characterization of central tendencies in inelastic displacements of steel structures under constant relative strength scenarios. In the following, the corresponding statistical results are presented and discussed for bi-linear, PR and CB systems.

\section{Bi-linear Models}

Figure 11 presents the COV of peak inelastic displacements for bi-linear structures over a range of initial elastic periods $(T / 1)$ and normalized periods $\left(T / T_{m}, T / T_{c}, T / T_{a v e r}, T / T_{g}\right.$ and $\left.T / T_{o}\right)$. It can be observed from Figure 11 that by considering the predominant period of the groundmotion $\left(T_{g}\right)$, the variability in the response is reduced rapidly (up to a COV of 0.3 at $T / T_{g}=1$ ) and is kept at lower levels over a wider range of structural periods. Other scalar frequency content parameters provide mixed merits in explaining variations in peak relative displacements, with $T_{m}$ and $T_{c}$ reducing the scatter for short period structures but increasing it for longer period systems. It can also be noted from Figure 11 that the smoothed predominant spectral period $\left(T_{o}\right)$ appears to be the least able to characterize frequency content effects on structural deformations. In turn, this reduction in the dispersion offers a clear advantage when differentiating among record bins on the basis of their frequency content. To this end, it can be shown [44] that earthquake suites defined in terms of $T_{g}$ follow a consistent pattern which is not achievable through the use of any of the other ground-motion period indicators considered.

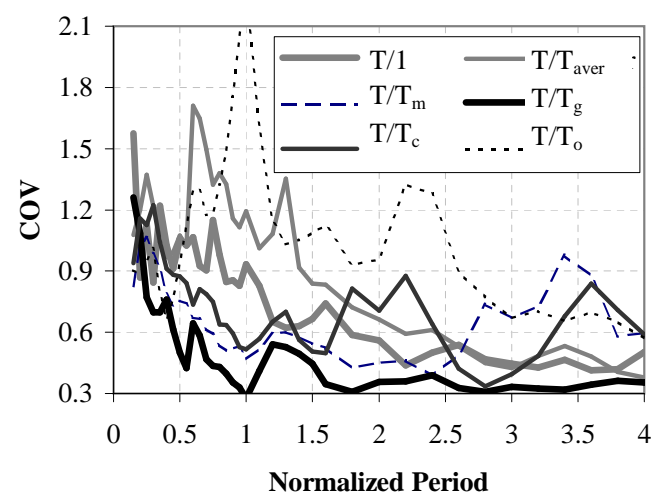

Figure 11. Coefficient of variation of inelastic displacement ratios of bi-linear systems for different normalized periods. $R=5$.

\section{PR Models}

Figure 12 presents the variation of the $\mathrm{COV}$ of $C_{R}$ ratios for PR systems normalized by different frequency content period indicators and for various levels of pinching. It is evident from Figure 12 that the consideration of ground-motion frequency content by means of $T_{g}$ reduces most considerably and consistently the dispersion associated with the estimation of peak deformations. As noted previously for bi-linear systems, in the case of PR structures the COV rapidly decreases to values below 0.3 at $T / T_{g}=1$ and is remarkably consistent and low for longer period structures regardless of the level of pinching. Normalization against other frequency content parameters seems to reduce the variability in displacement estimations to a lesser degree and only for limited period ranges. Similarly, this means that $T_{g}$ is better suited for distinguishing among earthquake accelerograms when estimating peak deformations in PR structures.

\section{CB Models}

Figure 13 presents the $\mathrm{COV}$ of the mean peak inelastic displacement ratios as a function of normalized periods for CB structures with braces of various normalized slenderness values. It can be observed from Figure 13 that overall, in the case of CB structures, the period normalization by 
$T_{g}$ continues to give lower dispersion values. This is particularly the case for $T / T_{g}>0.5$ in CB structures with braces of $\bar{\lambda}=0.9$ and for $T / T_{g}>1$ in CB structures with braces of $\bar{\lambda}=1.3$ or 1.7. Nevertheless, the reduction in COV is not as clearly beneficial over all periods as in the case of bi-linear or PR models. In particular, using $T_{m}$ or $T_{c}$ seem to be more effective for very short periods irrespective of the slenderness of the bracing system, and for normalized periods between 1.5 and 2.5 for CB models with $\bar{\lambda}=2.1$.

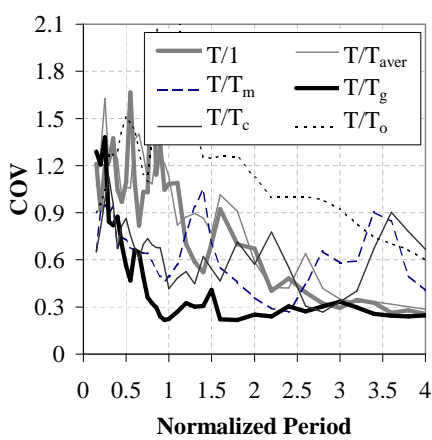

(a) $P=0.60$

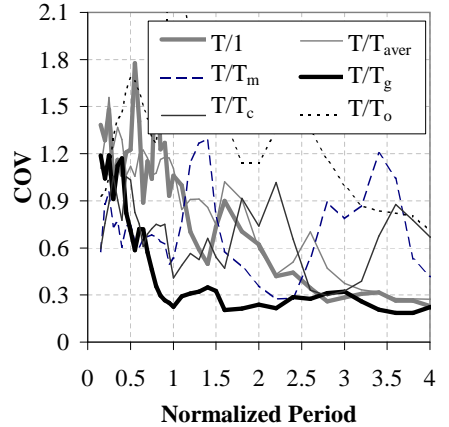

(b) $P=0.30$

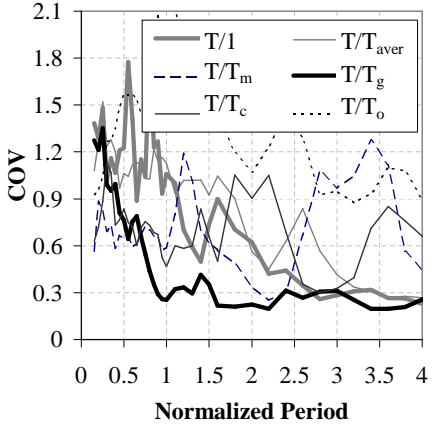

(c) $P=0.15$

Figure 12. Coefficient of variation of inelastic displacement ratios of PR systems for different normalized periods, $R=5$ and different Pinching Factors $P$.

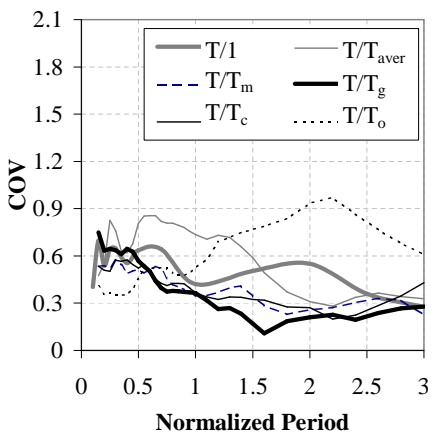

(a) $\bar{\lambda}=0.9$

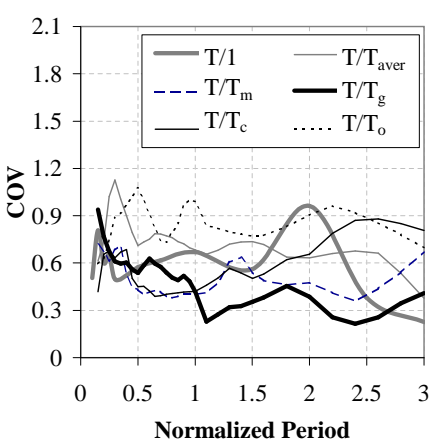

(c) $\bar{\lambda}=1.7$

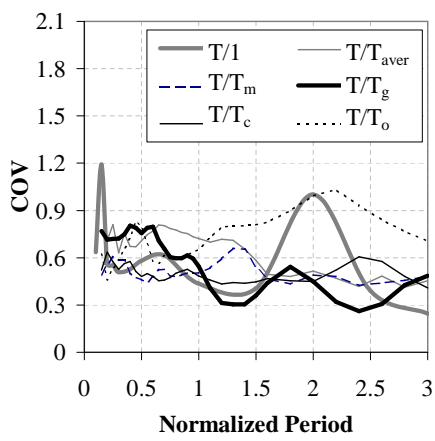

(b) $\bar{\lambda}=1.3$

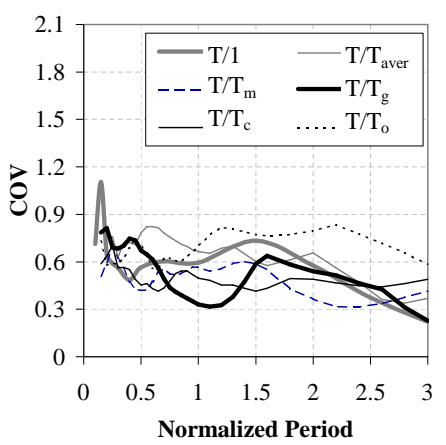

(d) $\bar{\lambda}=2.1$

Figure 13. Coefficient of variation of inelastic displacement ratios of CB systems for different normalized periods, $R=5$ and different normalized slenderness $\bar{\lambda}$. 


\section{PROPOSED EQUIVALENT LINEAR MODELS}

As discussed before, reliable estimation of peak displacements is a primary consideration in the seismic assessment of steel structures. To this end, the previous section has shown that the inclusion of a frequency content indicator leads to an improved characterization of central tendencies in inelastic displacement responses. Additionally, it has been argued [37] that equivalent linear systems based on secant periods offer several advantages over optimally defined equivalent systems, particularly in terms of enabling a direct and meaningful comparison of capacity and demand. In light of the above discussion as well as results presented in previous sections, this section proposes and examines expressions for equivalent period $\left(T_{e q}\right)$ and equivalent damping $\left(\xi_{e q}\right)$ parameters for $\mathrm{PR}$ and CB structures. The proposed equivalent linear models are based on the secant stiffness and aim to complement those suggested by Lin and Lin [37] for bi-linear systems.

\subsection{Non-iterative equivalent linearization models for steel structures}

The equivalent period $T_{e q}$ is defined hereafter as a function of the strength ratio $R$, the predominant period of the ground-motion $T_{g}$ and the initial structural period $T$ as:

$$
\begin{array}{ccc}
T_{e q} / T=\sqrt{\frac{(R-1) T_{g}+T}{1.6 T}} & \text { if } & T<T_{g} \\
T_{e q} / T=\sqrt{\frac{R T_{g}}{2.8 T_{g}-1.2 T}} & \text { if } & T_{g} \leq T \leq 1.5 T_{g} \\
T_{e q} / T=\sqrt{R} & \text { if } & T>1.5 T_{g}
\end{array}
$$

Equation 9 was obtained by employing strength-ductility relationships for target ductility scenarios over normalized periods $\left(T / T_{g}\right)$ as described in detail elsewhere [44]. In those simplified relationships, the strength ratio $R$ was observed to increase from a value of 1 at $T / T_{g} \approx 0$ to 1.6 times the ductility $(\mu)$ at $T / T_{g}=1$ before keeping a constant value of $R=\mu$ for period ratios greater than $T / T_{g}=1.5$.

On the basis of the extensive database generated in the course of this study and considering an equivalent period defined by Equation 9, it is possible to determine an equivalent damping ratio $\left(\xi_{e q}\right)$ for each period-displacement pair that would minimize the error in peak deformation estimations. Multivariate regression analyses can then be performed in order to develop prediction expressions for mean equivalent viscous damping values [37]. The equivalent damping expressions obtained from such regression analyses are given below for PR and CB models. Importantly, the high variability and peculiar features of structural response observed for soft soils in the previous sections, calls for dedicated models which are the subject of current research. Accordingly, only data for moderate to stiff soils sites (70 records) were used in the computation of the regression expressions for equivalent damping presented herein.

\section{Equivalent Damping for PR Models}

For PR structures with $T \leq 1.0$ second, the equivalent damping can be estimated as:

$$
\begin{gathered}
\xi_{e q}=0.05+a e^{b T} \\
a=1.425 R^{-0.25} \\
b=(0.28+P / 1.5) \ln (R)-2.7
\end{gathered}
$$

Whereas for PR structures with $T \geq 2.0$ seconds:

$$
\begin{gathered}
\xi_{e q}=0.05+a \ln (R)+b \\
a=0.0299 P+0.14 \\
b=0.02826
\end{gathered}
$$

Values for PR structures with $1<T<2$ seconds can be found by linear interpolation. 


\section{Equivalent Damping for CB Models}

Similarly, expressions for the estimation of equivalent damping in CB systems with $T \leq 1.5$ seconds can be established as follows:

$$
\begin{gathered}
\xi_{e q}=0.05+a \ln (T)+b \\
a=-0.053 R-0.054 \geq-0.27 \\
b=0.95 R^{-0.79}
\end{gathered}
$$

For the estimation of equivalent damping for $\mathrm{CB}$ structures with elastic period greater than $T>1.5$ seconds, the value of $\xi_{e q}(T=1.5)$ can be assumed to be applicable. In light of the minor dependence of CB peak displacements on the normalized brace slenderness $(\bar{\lambda})$ and the high variability in the response observed (e.g. Figure 13), Equation 12 does not incorporate a slenderness regression function.

\subsection{Verification and application}

The accuracy of Equations 9 to 12 to predict peak displacement demands can be evaluated by the median ratio $(E)$ of approximate $\left(\delta_{a p}\right)$ to exact $\left(\delta_{e x}\right)$ peak inelastic displacements defined as:

$$
E\left(T, R, \alpha, T_{g}\right)=\operatorname{med}\left(\frac{\delta_{a p}\left(T_{e q}, \xi_{e q}\right)}{\delta_{e x}\left(T, \xi, R, \alpha, T_{g}\right)}\right)
$$

where $\delta_{e x}$ is determined from detailed non-linear response history analysis.

A value of $E$ close to 1 indicates that the proposed equivalent linear model accurately describes the displacement response, whereas values of $E<1$ or $E>1$ represent under or overestimations of peak displacement, respectively. With reference to the previously-generated dataset, for a given structural period $T$, strength ratio $R$ and ground-motion predominant period $T_{g}$, the equivalent period (from Equation 9) and damping (from Equations 10 to 12) can be calculated. Subsequently, the approximate peak inelastic displacement $\left(\delta_{a p}\right)$ can be estimated from the response spectra of the equivalent linear system. Based on such approximate peak inelastic displacement and the exact values of peak deformations, values of $E$ were computed for a range of systems, strength reduction factors and hysteretic models for the 70 ground-motion records on moderately stiff to stiff soils employed in this study.

Figure 14 shows the median ratio of approximate to exact peak inelastic displacements for PR systems with different pinching levels and for different strength demands while Figure 15 presents the corresponding Coefficients of Variation (COV). Similarly, Figure 16 presents median ratios of approximate to exact peak displacement for $\mathrm{CB}$ structures of varying slenderness and strength factors while the associated COV are depicted in Figure 17. In general, Equations 9 to 12 were found to provide reasonable estimations of peak displacements for a wide range of periods. It can be seen from Figure 14 that the proposed PR equivalent linear models provide reliable estimations (i.e. within $\pm 20 \%$ ) for structures with periods greater than approximately 0.20 second whereas notable under-predictions would be expected for very stiff PR structures (i.e. $T=0.1$ or 0.15 second). These reasonable estimates could be observed irrespectively of the strength demand ratio or the level of pinching in the system (Figure 14). In the same way, peak displacement estimations within $\pm 20 \%$ would be expected for CB systems with $\bar{\lambda}=1.3$ or 1.7 for periods greater than 0.20 second while higher levels of discrepancies may arise for specific combinations of strength demands and period ranges like for $R=2$ and $T \leq 0.8$ when $\bar{\lambda}=0.9$. Nonetheless, notable over-estimations would be expected for very stiff $\mathrm{CB}$ structures, characterized by periods lower than 0.2 second (i.e. $\mathrm{T}=0.1$ and 0.15 second) in all cases (Figure 16).

Equations 9 to 12 seem to adequately cover a wide range of practical $\mathrm{CB}$ and $\mathrm{PR}$ structural configurations. In effect, by using the equivalent models of Equations 9 to 12, there is a significantly low level of scatter in the peak displacement estimations for PR structures over the whole period range under study (e.g. by comparing the COV of $T / 1$ in Figure 12 with the corresponding curves in Figure 15). However, the improvement is less significant for the dispersion of peak deformation 
estimations in $\mathrm{CB}$ systems (e.g. by comparing the COV of $T / 1$ in Figure 13 with the corresponding curves in Figure 17) while the scatter in the short period range remains important for both PR and CB systems. In particular, the increased levels of error observed for $T \leq 0.2$ second in Figures 14 and 16 can be attributed to the higher levels of response variability which are associated with this very short period range. Further refinements for very short period structures should be explored in future studies. Such studies should also consider a larger set of records as well as a finer period discretization (i.e. shorter period intervals of $\Delta T \leq 0.01$ second for $T \leq 0.2$ second).

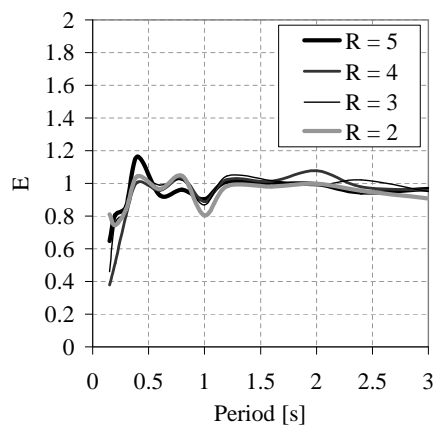

(a) $P=0.6$

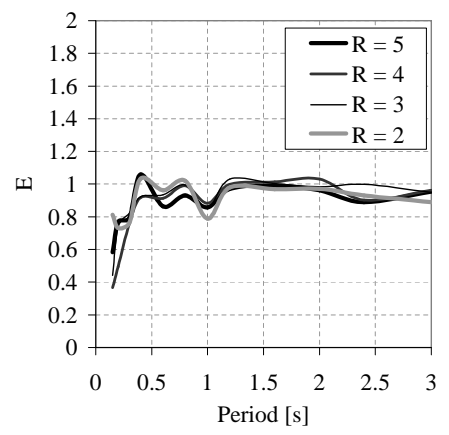

(b) $P=0.3$

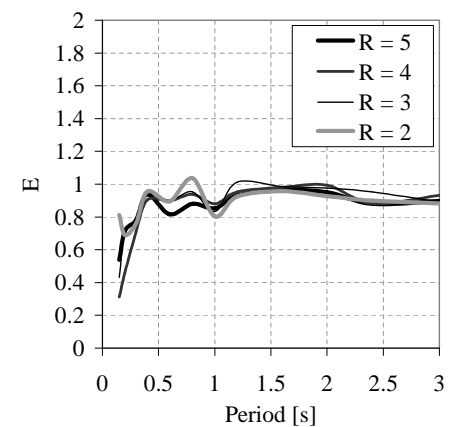

(c) $P=0.15$

Figure 14. Median ratio of approximate to exact $\left(\delta_{a p} / \delta_{e x}\right)$ peak inelastic displacements for PR models.

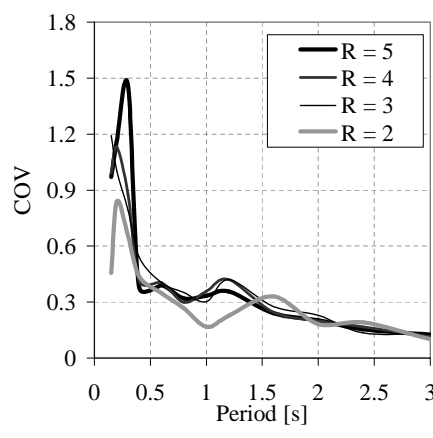

(a) $P=0.6$

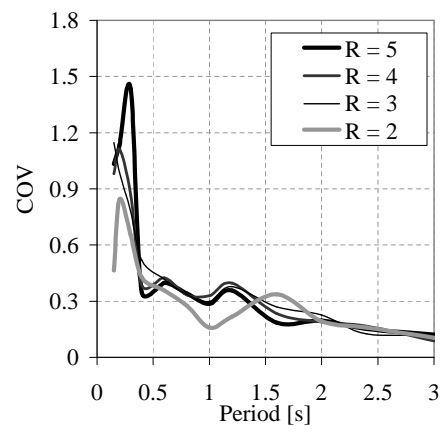

(b) $P=0.3$

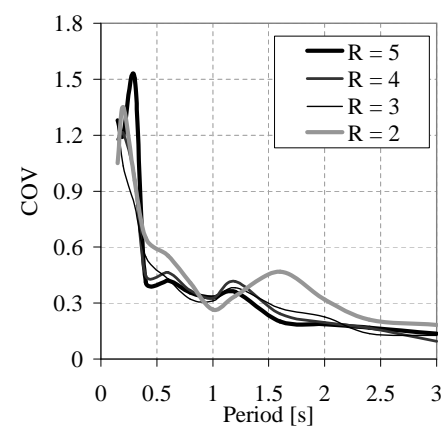

(c) $P=0.15$

Figure 15. COV of approximate to exact $\left(\delta_{a p} / \delta_{e x}\right)$ peak inelastic displacements for PR models.

In order to illustrate the use of the equivalent linearization expressions, the assessments of a 6storey 5-bay CB frame and a 2-storey 6-bay CB building are presented as examples. The buildings were designed and modelled by Málaga-Chuquitaype et al. [46,47] and have initial periods of 1.1 second (6-storey frame) and 0.22 second (2-storey frame) obtained from Eigenvalue analysis. The slenderness of the first-storey braces are $\bar{\lambda}=1.3$ for the 6-storey building and $\bar{\lambda}=1.1$ for the 2 -storey frame. Figures 18a and 19a show schematic views of the buildings under consideration together with their corresponding base shear versus roof drift curves derived from non-linear static (pushover) analyses. The response to El Centro record with $T_{g}=1.95$ seconds is considered herein.

In the case of the 6-storey $\mathrm{CB}$ frame, the record was scaled to have a $P G A$ to acceleration at yield ratio equal to 3, which corresponds to a strength ratio $R=7.26$ [47]. According to Equation 9, the $T_{e q} / T$ ratio can be estimated as 2.74 (i.e. $T_{e q}=3$ seconds). By means of Equation 12, coefficients $a$ and $b$ are evaluated as -0.27 and 0.2 , respectively, and the resulting equivalent viscous damping is $\xi_{e q}=22 \%$. Figure 18b presents the demand diagram for this 6-storey CB structure. It can be observed that the equivalent linearized model predicts a roof displacement of approximately 95 $\mathrm{cm}$ which should be compared with the $102 \mathrm{~cm}$ obtained from refined non-linear response history analysis [47]. 


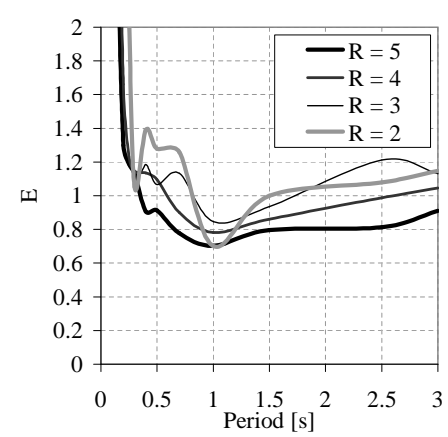

(a) $\bar{\lambda}=0.9$

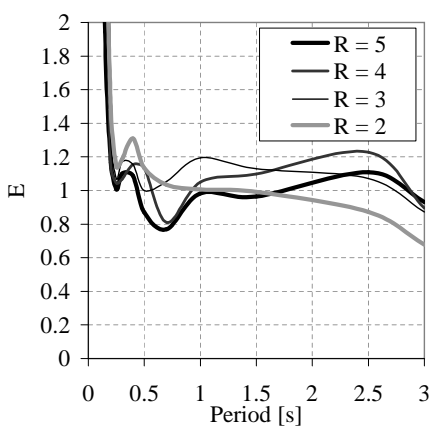

(c) $\bar{\lambda}=1.7$

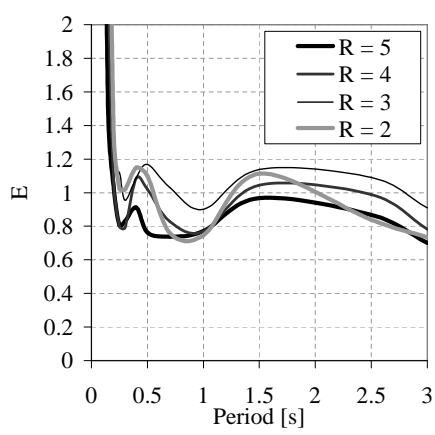

(b) $\bar{\lambda}=1.3$

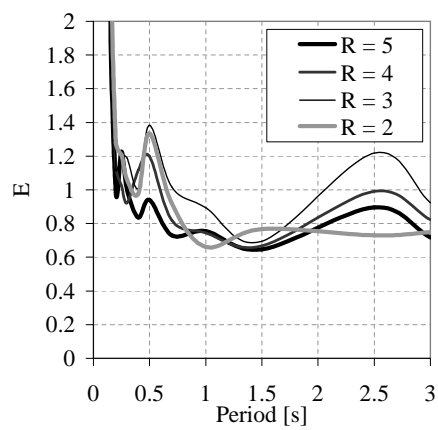

(d) $\bar{\lambda}=2.1$

Figure 16. Median ratio of approximate to exact peak inelastic displacements for CB models.

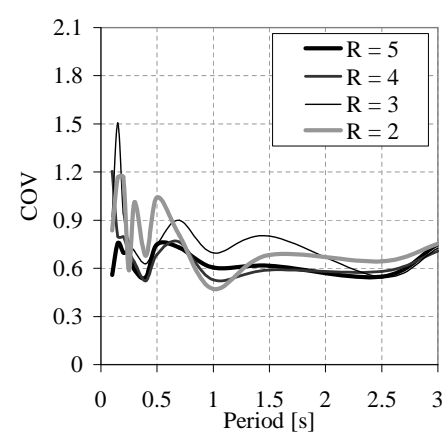

(a) $\bar{\lambda}=0.9$

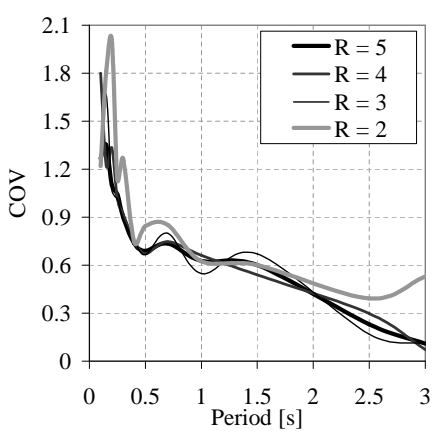

(c) $\bar{\lambda}=1.7$

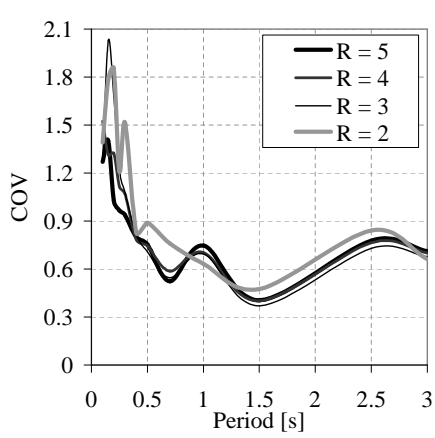

(b) $\bar{\lambda}=1.3$

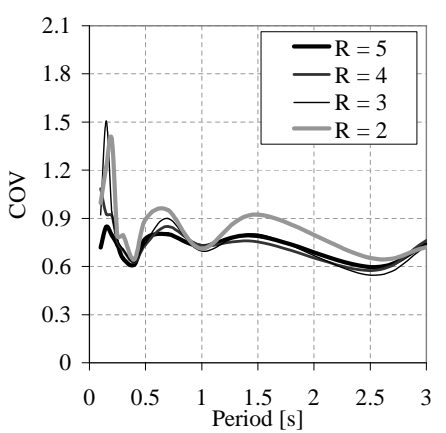

(d) $\bar{\lambda}=2.1$

Figure 17. COV of approximate to exact $\left(\delta_{a p} / \delta_{e x}\right)$ peak inelastic displacements for CB models. 
Similarly, in the case of the 2-storey building the record was scaled in order to get a strength ratio of $R=3$. Equation 9 leads to a $T_{e q} / T$ ratio of 3.42 (i.e. $T_{e q}=0.75$ second) while Equation 12 estimates the coefficients $a$ and $b$ as -0.21 and 0.39 , respectively, resulting in an equivalent viscous damping of $\xi_{e q}=77 \%$. Figure 19b presents the demand diagram for this 2-storey CB structure from which a peak displacement of $10 \mathrm{~cm}$ is obtained, comparable to the the $7.9 \mathrm{~cm}$ displacement obtained from refined non-linear response history analysis [46]. The good predictions obtained here serve only to exemplify the applicability of the proposed models in estimating peak displacement demands. However, the validity of the proposed linearized model clearly needs to be examined further in future studies covering more buildings and within a comprehensive probabilistic context.

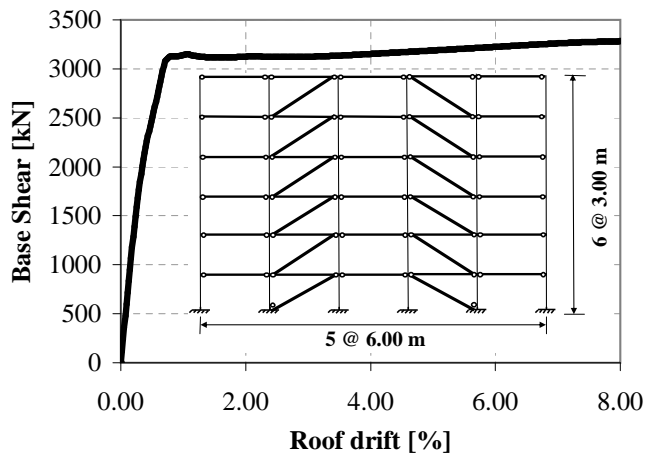

(a) Pushover curve of the 6-storey 5-bay CB frame.

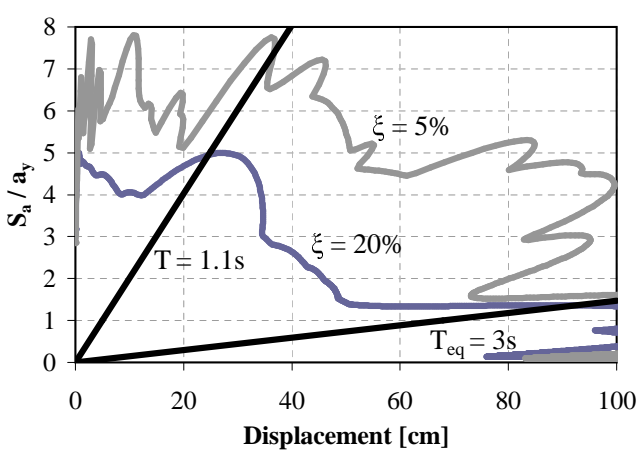

(b) Demand and capacity diagrams.

Figure 18. Application of the equivalent linearization on the displacement estimation of a 6-storey structure with $R=7.26$.

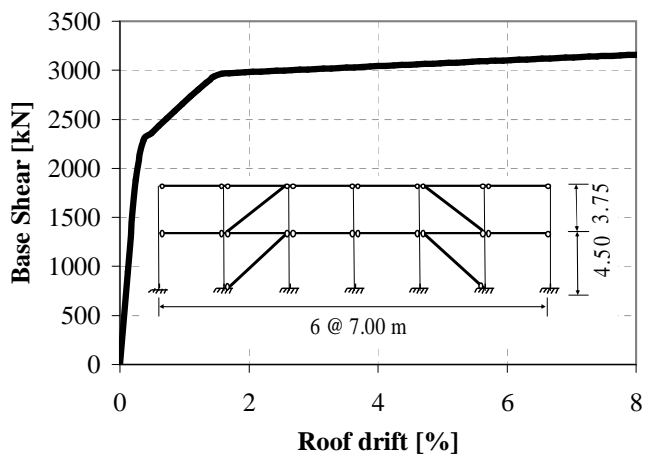

(a) Pushover curve of the 2-storey 7-bay CB frame.

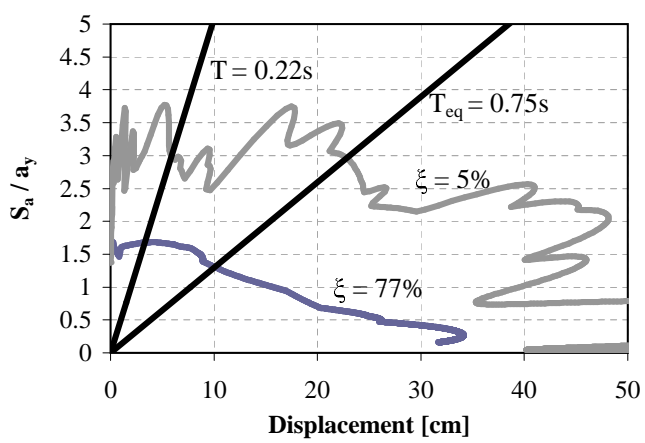

(b) Demand and capacity diagrams.

Figure 19. Application of the equivalent linearization on the displacement estimation of a 2-storey structure with $R=3$.

\section{CONCLUDING REMARKS}

This paper has examined the inelastic displacement response of steel framed structures of known levels of strength when subjected to a relatively large number of ground-motions. SDOF systems with three hysteretic responses were analysed: (i) bi-linear systems typical of moment resisting structures, (ii) Modified Richard-Abbott models representative of partially restrained (PR) frames, and (iii) fiber-based models simulating concentrically-braced (CB) framed structures. The influence of model characteristics, level of inelastic behaviour and soil conditions on peak displacement ratios has been discussed. 
The study revealed key differences in the inelastic deformation demands between bi-linear, PR and CB models, particularly in the relatively short period spectral region. The ratio between the overall yield strength and the strength during pinching intervals was found to be the main factor governing the inelastic deformations of PR models when compared with bi-linear model predictions. PR models can exhibit higher displacement demands that may reach more than double the peak displacements estimated through bi-linear models for relatively stiff structures. Despite their similar cyclic force-displacement relationships, the seismic response of CB and PR models was observed to follow different tendencies, with the rate of displacement amplifications decreasing as the strength ratio increases for $\mathrm{CB}$ models when compared against bi-linear predictions. It was found that the effects of local site conditions on displacement ratios are relatively small for moderately stiff to stiff soils, whereas significant displacement amplifications occur in the case of soft soils relative to stiffer sites.

A study on the influence of a number of scalar parameters that characterize the frequency content of the ground-motion on the estimated peak displacement ratios was performed. The predominant period of the ground-motion $\left(T_{g}\right)$ was found to be clearly more effective in reducing the variability and thus enhancing the accuracy of peak inelastic displacement estimations in bi-linear and PR structures when compared with other scalar frequency indicators such as average spectral period $T_{\text {aver }}$, mean period $T_{m}$, characteristic period $T_{c}$ and smoothed spectral predominant period $T_{o}$. As for CB structures, the inclusion of $T_{g}$ reduces the dispersion in peak displacements for $T / T_{g}>0.5$ in $\mathrm{CB}$ structures with more stocky braces (i.e. $\bar{\lambda}=0.9$ ) while significant improvements are also evident for $T / T_{g}>1$ in CB structures with $\bar{\lambda}=1.3$ or 1.7 . Nevertheless, the reduction in COV is not as consistent over all periods as in the case of bi-linear or PR models.

Finally, non-iterative equivalent linearization expressions for the estimation of peak deformations on SDOF systems with known strength were proposed. In light of the findings of this study, the equivalent linear system proposed was defined as a function of the strength ratio $R$, the predominant period of the ground-motion $T_{g}$ and the structural initial elastic period $T$. The developed equations were validated by examining the range of estimated over exact peak displacements. These prediction equations appear to be reliable (i.e within $\pm 20 \%$ average error) for the assessment of steel structures with $T>0.20$. However, further validation studies are needed to cover a wider range of structural configurations, as well as to incorporate expressions covering soft soil conditions.

\section{REFERENCES}

1. ATC. Improvement of nonlinear static seismic analysis procedures, Report FEMA-440 2005.

2. Miranda E. Seismic evaluation and upgrading of existing buildings. PhD Thesis, University of California at Berkeley, Berkeley, US 1991.

3. Qi X, Mohele J. Displacement design approach for reinforced concrete structures subjected to earthquakes, Report EERC/UCB-91/02. Technical Report, Earthquake Engineering Research Center, University of California at Berkeley, Berkeley, US 1991.

4. Málaga-Chuquitaype C, Bommer JJ, Pinho, R, Stafford, PJ. Selection and scaling of real ground-motion records for nonlinear response-history analyses based on equivalent SDOF systems. Proceedings of the Fourteenth World Conference on Earthquake Engineering, China, Paper Paper ID: 05-01-0064.

5. Comité Européen de Normalisation. EN 1998-1, Eurocode 8: Design of structures for earthquake resistance, Part 1: General rules, seismic actions and rules for buildings 2005.

6. FEMA. Recommended seismic design criteria for new steel moment-frame buildings 2000.

7. Vidic M, Fajfar P, Fischinger M. Consistent inelastic design spectra: strength and displacement. Earthquake Engineering and Structural Dynamics 1994; 23(5):507-521.

8. Miranda E. Inelastic displacement ratios for structures on firm sites. Journal of Structural Engineering, American Society of Civil Engineering 2000; 126(10):740-757.

9. Ruiz-Garcia J, Miranda E. Inelastic displacement ratios for evaluation of existing structures. Earthquake Engineering and Structural Dynamics 2003; 32:1237-1258.

10. Ruiz-Garcia J, Miranda E. Inelastic displacement ratios for design of structures on soft soils sites. Journal of Structural Engineering, American Society of Civil Engineering 2004; 130(12):2051-2061.

11. Chopra A, Chintanapakdee C. Inelastic deformation ratios for design and evaluation of structures: single-degreeof-freedom bilinear systems. Journal of Structural Engineering, American Society of Civil Engineering 2004; 130(9):1309-1319.

12. Ruiz-Garcia J, Miranda E. Inelastic displacement ratios for evaluation of structures built on soft soil sites. Earthquake Engineering and Structural Dynamics 2006; 35:679-694. 
13. Vamvatsikos D, Cornell C. Direct estimation of the seismic demand and capacity of oscillators with multi-linear static pushovers through IDA. Earthquake Engineering and Structural Dynamics 2006; 35(9):1097-1117.

14. Bozorgnia Y, Hachem MM, Campbell KW. Deterministic and probabilistic predictions of yield strength and inelastic displacement spectra. Earthquake Spectra 2010; 26(1):25-40.

15. Veletsos A, Newmark NM. Effect of inelastic behaviour on the response of simple systems to earthquake motions. Proceedings of the Second World Conference on Earthquake Engineering, Japan, vol. 2, 1960; 895-912.

16. Newmark NM, Hall W. Earthquake spectra and design. Technical Report, Earthquake Engineering Research Institute, Oakland, California 1982.

17. Song J, Pincheira J. Spectral displacement demands of stiffness-degrading and stregth-degrading systems. Earthquake Spectra 2000; 16(4):817-851.

18. Miranda E, Ruiz-Garcia J. Influence of stiffness degradation on strength demands of structures built on soft soils sites. Engineering Structures 2002; 24(10):1271-1281.

19. Goda K, Hong H, Lee C. Probabilistic characteristics of seismic ductility demand of sdof system with Bouc-Wen hysteretic behavior. Journal of Earthquake Engineering 2009; 13:600-622.

20. Elghazouli AY, Málaga-Chuquitaype C, Castro JM, Orton AH. Experimental monotonic and cyclic behaviour of blind-bolted angle connections. Engineering Structures 2009; 31(11):2540-2553.

21. Málaga-Chuquitaype C, Elghazouli AY. Behaviour of combined channel/angle connections to tubular columns under monotonic and cyclic loading. Engineering Structures 2010; 32(11):1600-1616.

22. Elghazouli AY, Broderick BM, Goggins JM, Mouzakis H, Carydis P, Bouwkamp J, Plumier A. Shake table testing of tubular steel bracing members. Proceedings of the Institution of Civil Engineers, Structures and Buildings 2005; SB4:229-241.

23. Chopra A, Chintanapakdee C. Comparing response of sdf systems to near-fault and far-fault earthquake motions in the context of spectral regions. Earthquake Engineering and Structural Dynamics 2001; 30(12):1769-1798.

24. Miranda E. Site-dependent strength-reduction factors. Journal of Structural Engineering, American Society of Civil Engineering 1993; 119(12):3503-3519.

25. Shimazaki K, Sozen M. Seismic drift of reinforced concrete structures. Technical Report, Hazama-Gumi, Ltd. 1984.

26. Uang C, Maarouf A. Evaluation of displacement amplification factor for seismic design provisions. Technical Report, Department of Civil Engineering, Northeastern University, Boston, US 1996.

27. Tiwari A, Gupta V. Scaling of ductility and damage-based stregth reduction factors for horizontal motions. Earthquake Engineering and Structural Dynamics 2000; 29:969-987.

28. Chakraborti A, Gupta V. Scaling of strength reduction factors for degrading elasto-plastic oscillators. Earthquake Engineering and Structural Dynamics 2005; 34:189-206.

29. Rathje E, Faraj F, Russell S, Bray J. Empirical relationships for frequency content parameters of earthquake ground motions. Earthquake Spectra 2004; 20(1):119-144.

30. FEMA. NEHRP guidelines for the seismic rehabilitation of buildings, Report FEMA-273, Washington, US 1997.

31. ATC. Seismic evaluation and retrofit of concrete buildings, Report ATC-40, california, us 1994.

32. Comité Européen de Normalisation. EN 1998-3, Eurocode 8: Design of structures for earthquake resistance, Part 3: Assessment and retrofit of buildings 2005.

33. Gulkan P, Sozen M. Inelastic response of reinforced concrete structures to earthquake actions. ACI Journal 1974; 71:604-610.

34. Dwairi H, Kowalsky M, Nau J. Equivalent damping in support of direct displacement based-design. Journal of Earthquake Engineering 2007; 11(4):512-530.

35. Kwan W, Billington S. Influence of hysteretic behavior on equivalent period and damping of structural systems. Journal of Structural Engineering, American Society of Civil Engineering 2003; 129(5):576-585.

36. Guyader A. A statistical approach to equivalent linearization with application to performance-based engineering. PhD Thesis, California Institute of Technology, California, US 2003.

37. Lin Y, Lin Y. Non-iterative equivalent linearization based on secant period for estimating maximum deformations of existing structures. Journal of Earthquake Engineering 2009; 13:170-192.

38. Goda K, Atkinson G. Non-iterative equivalent linearization of inelastic sdof systems for earthquakes in japan and california. Earthquake Engineering and Structural Dynamics 2010; 39(11):1219-1238.

39. Nogueiro P, Simoes da Silca L, Bento R, Simoes R. Numerical implementation and calibration of a hysteretic model with pinching for the cyclic response of steel joints. International Journal of Advanced Steel Construction 2007; 3:459-484.

40. Richard R, Abbott B. Versatile elasto-plastic stress-strain formula. Journal of the Engineering Mechanics Division, American Society of Civil Engineering 1975; 101(EM4):511-515.

41. McKenna F. Object oriented finite element programming: Frameworks for analysis, algorithms and parallel computing. PhD Thesis, University of California, Berkeley, Berkeley, CA, US. http://opensees.berkeley.edu 1997.

42. Uriz P, Mahin S. Towards earthquake-resistant design of concentrically braced steel-frame structures PEER Report 2008/08. Technical Report, Pacific Earthquake Engineering Research Center, University of California at Berkeley, California, US 2008.

43. Nip KH, Gardner L, Elghazouli AY. Cyclic testing and numerical modelling of carbon steel and stainless steel tubular bracing members. Engineering Structures 2010; 32:424-441.

44. Málaga-Chuquitaype C. Seismic behaviour and design of steel frames incorporating tubular members. PhD Thesis, Department of Civil and Environmental Engineering, Imperial College London, London, UK 2011.

45. Comité Européen de Normalisation. EN 1993-1-1, Eurocode 3: Design provisions of steel structures, Part 1.1: General rules and rules for buildings 2005.

46. Málaga-Chuquitaype C. Rigid-plastic models for the seismic design and assessment of steel frames. Technical Report, Department of Civil and Environmental Engineering, Imperial College London, London, UK 2008.

47. Málaga-Chuquitaype C, Elghazouli AY, Bento R. Rigid-plastic models for the seismic design and assessment of steel framed structures. Earthquake Engineering and Structural Dynamics 2009; 38(11):1609-1630. 